MARCO ANTÔNIO BRASIEL SAMPAIO

\title{
MECÂNICA DO CONTATO COM O MÉTODO DOS ELEMENTOS DE CONTORNO PARA MODELAGEM DE MÁQUINAS TUNELADORAS
}

Dissertação apresentada à Escola Politécnica da Universidade de São Paulo como parte dos requisitos para a obtenção do título de Mestre em Engenharia de Estruturas

São Paulo 


\section{MECÂNICA DO CONTATO COM O MÉTODO DOS ELEMENTOS DE CONTORNO PARA MODELAGEM DE MÁQUINAS TUNELADORAS}

Dissertação apresentada à Escola Politécnica da Universidade de São Paulo como parte dos requisitos para a obtenção do título de Mestre em Engenharia de Estruturas

Área de concentração:

Engenharia de Estruturas.

Orientador:

Prof. Dr. Marcos Aurélio Marques Noronha.

São Paulo 
Este exemplar foi revisado e alterado em relação à versão original, sob responsabilidade única do autor e com a anuência de seu orientador.

São Paulo, de dezembro de 2009.

Assinatura do autor

Assinatura do orientador

FICHA CATALOGRÁFICA

Sampaio, Marco Antônio Brasiel

Mecânica do contato com o método dos elementos de contorno para modelagem de máquinas tuneladoras / M.A.B.

Sampaio. -- ed.rev. -- São Paulo, 2009.

$71 \mathrm{p}$.

Dissertação (Mestrado) - Escola Politécnica da Universidade de São Paulo. Departamento de Engenharia de Estruturas e Geotécnica.

1. Método dos elementos de contorno 2. Túneis I. Universidade de São Paulo. Escola Politécnica. Departamento de Engenharia de Estruturas e Geotécnica II. t. 
DEDICATÓRIA

Aos meus pais, Fernando $e$ Eládia, e aos meus irmãos, Marco Túlio e Lito. 


\section{AGRADECIMENTOS}

Aos meus pais, Fernando Antonio Alves Sampaio e Eládia Maria Brasiel Sampaio, pelos ensinamentos sobre a vida, pela amizade e apoio incessante durante todo o mestrado.

Aos meus irmãos, Marco Túlio e Fernando, os amigos que terei por toda a vida, que sempre me incentivaram nas escolhas que fiz.

A Hellen, pela compreensão e por estar ao meu lado nos momentos que precisei.

Ao Tio Beto e à Tia Deila que, apesar da distância, sempre lembraram e se fizeram presente.

Ao Professor Noronha, por ter confiado em meu trabalho e por sua dedicação e incentivo à pesquisa.

Ao André Brabo, uma pessoa que admiro muito pelo seu conhecimento e humildade, que me auxiliou em grande parte do meu trabalho.

Aos companheiros do LMC, em especial ao grande amigo Társis Travassos que esteve comigo desde o início do mestrado, pelos conselhos e conhecimento compartilhado.

Aos meus amigos aracajuanos aqui em São Paulo com os quais compartilhei grandes momentos.

À CAPES pela bolsa de pesquisa. 


\section{RESUMO}

Uma implementação computacional baseada nos conceitos da mecânica do contato e no Método dos Elementos de Contorno é desenvolvida para simular a interação entre discos de corte e maciço rochosos.

Simula-se o contato considerando-se inicialmente uma superfície potencial de contato que é atualizada durante um processo de carregamento incremental, podendo conter elementos separados, em contato sem deslizamento ou com deslizamento parcial. A cada passo do carregamento incremental estima-se a configuração do modelo e os dados obtidos neste passo serão utilizados como parâmetros no passo seguinte até que todo o carregamento esteja aplicado.

O modelo em estudo consiste em dois discos de corte paralelos atuando sobre uma base sólida com característica elástica linear. São feitas duas simulações com os discos de corte. Na primeira delas, compara-se a penetração dos discos utilizando-se como parâmetro os valores calculados em uma análise por elementos finitos. No segundo caso, estuda-se a distribuição de tensões no maciço quando se altera o espaçamento entre os discos para um mesmo carregamento.

Além desta análise, duas outras comparações são feitas utilizando como parâmetros soluções analíticas e numéricas de modelos clássicos da mecânica do contato. São estes: cilindro e pilar em base elástica.

Palavras-chave: Máquinas Tuneladoras (TBMs); Método dos Elementos de Contorno; Mecânica do Contato, Discos de corte. 


\begin{abstract}
A computational implementation based on contact mechanics and on the Boundary Element Method is developed in order to simulate the interaction between disc cutters and rock mass.

The contact simulation considers initially a potential contact area which is updated during an incremental load process, in such way the surface can include elements in separation, stick or partial slip. At each incremental load step the configuration of the model shall be evaluated and the values computed at such step are used as parameter to the next load step until the end of the loading process.

The investigated model consists in two parallel cutter discs on a flat elastic foundation. In the first simulation the penetration of the discs are studied and the results are compared against a finite element simulation. In the second simulation, the stress distribution in the rock mass is evaluated considering different spacing between the disc cutters by keeping the same load.

In addition, two benchmark problems of contact mechanics, such as the cylinder and the flat punch on a elastic foundation, were modeled in order to validate the proposed algorithm. The obtained results were compared against analytical and numerical solutions.
\end{abstract}

Keywords: Tunnel Boring Machines; Boundary Element Methods; Contact Mechanics, Disc cutters. 


\section{LISTA DE TABELAS}

Tabela 6.1 - Parâmetros dos materiais do cilindro e base. 55

Tabela 6.2 - Comparação dos valores de penetração do pilar em uma fundação elástica. ......58

Tabela 6.3 - Discretizações pelo MEC e MEF. .......................................................................... 61

Tabela 6.4 - Comparação dos valores de penetração do pilar em uma fundação elástica. .......62 


\section{LISTA DE FIGURAS}

Figura 2.1 - Esquematização da TBM: discos de corte, cabeça de corte e sapata de fixação. 25

Figura 2.2 - Representação da fragmentação causada pelos discos de corte. 26

Figura 2.3 - Concentração de tensão causada pelas sapatas de fixação.

Figura 2.4 - Formatos de discos de corte. (a) disco em forma de "V". (b) disco de seção constante.

Figura 3.1 - Sólido em equilíbrio submetido a deslocamentos e forças prescritas. 30

Figura 3.2 - Tensões atuantes nas faces de um elemento cúbico infinitesimal.........................30

Figura 3.3 - Forças em uma superfície infinitesimal com orientação arbitrária. 31

Figura 4.1 - Subdomínios (a) sólido; (b) divisão do sólido em subdomínios (c) subdomínios discretizados.

Figura 5.1 - Contato sem atrito. (a) contato com lubrificante. (b) forças na superfície de contato.

Figura 5.2 - Contato com atrito. (a) forças em situação tipo stick. (b) forças em situação tipo slip.

Figura 5.3 - Tipos de contato: (a) Contato conforme. (b) Contato não-conforme.

Figura 5.4 - Representação de dois sólidos em um problema de contato. (a)Sólidos A e B. (b)

Discretização pelo MEC. (c) Sólidos A e B em contato.

Figura 5.5 - Representação da superfície de contato, dos pares de nós e modos de contato...49

Figura 5.6 - Algoritmo de contato.

Figura 6.1 - Indentação de um cilindro em uma superfície elástica. .53

Figura 6.2 - Cilindro em fundação elástica. 54

Figura 6.3 - Distribuição da tensão normal na superfície de contato... 56

Figura 6.4 - Pilar apoiado em uma fundação elástica. .57

Figura 6.5 - Discretizações com o MEC e MEF. (a)MEC - 78 elementos e 70 nós. (b) MEF 65 elementos e 297 nós. (c) MEF - 6.000 elementos e 24.341 nós.

Figura 6.6 - Configuração deformada de um pilar sobre base flexível. (a) Pilar rígido. (b) Pilar e base flexíveis.

Figura 6.7 - Zonas de tensão. (a) MEC. (b) MEF - 65 elem. e 297 nós. (c) MEF - 6.000 elem. e 24.431 nós.

Figura 6.8 - Discos de corte paralelos.

Figura 6.9 - Evolução das tensões entre dois discos de corte com a diminuição do espaçamento.

Figura 6.10 - Discos de corte em espaçamentos diferentes. 


\section{LISTA DE ABREVIATURAS E SIGLAS}

GUI Interface Gráfica com o Usuário (Graphical User Interface)

MEC Método dos Elementos de Contorno

MED Método dos Elementos Discretos

MEF Método dos Elementos Finitos

OO Orientação a Objeto

POO Programação Orientada a Objetos (Object Oriented Programation)

TBM Máquina tuneladora (Tunnel Boring Machine) 
LISTA DE SÍMBOLOS 
$S_{v} \quad$ Região onde são conhecidas as forças de superfície

$S_{u} \quad$ Região onde são conhecidos os deslocamentos

$b_{i} \quad$ Forças de volume

$P \quad$ Ponto qualquer

$\sigma_{i j} \quad$ Componentes do tensor das tensões

$[T] \quad$ Tensor das tensões de Cauchy

$t_{i} \quad$ Forças de superfície

$n_{j} \quad$ Cosseno diretor

n Vetor normal

u Vetor deslocamento

$\Omega \quad$ Domínio

$e_{i} \quad$ Direção principal

$\varepsilon \quad$ Vetor de Deformação

$\varepsilon_{i j} \quad$ Componentes do vetor de deformação

$\lambda, \mu \quad$ Coeficientes de Lamé

$v \quad$ Coeficiente de Poisson

E Módulo de elasticidade longitudinal

$\delta_{i j} \quad$ Delta de Kronecker

$\Gamma \quad$ Contorno

$p_{k} \quad$ Força de superfície

$\bar{u} \quad$ Deslocamento conhecido

$\bar{p} \quad$ Força de superfície conhecida

* Solução fundamental, representa os deslocamentos em qualquer ponto na

$u_{l k}^{*} \quad$ direção K, quando uma carga unitária é aplicada na fonte, na direção 1

Solução fundamental, representa as forças em qualquer ponto na direção K,

$p_{l k}^{*} \quad$ quando uma carga unitária é aplicada na fonte, na direção 1

Distância entre o ponto em que $u_{l k}^{*}$ e $p_{l k}^{*}$ são observados e o ponto em que a

força unitária é aplicada

$\varepsilon \quad$ Raio da circunferência que aproxima a superfície em um nó do contorno

Termo livre, coeficiente que depende da geometria do contorno na

$c^{i} \quad$ vizinhança do nó $i$ e material

Ф Matriz de funções de interpolação 
H Matriz característica do MEC densa e não-simétrica

G Matriz característica do MEC densa e não-simétrica

A Matriz formada por colunas de $\mathrm{He} \mathrm{G}$

Vetor formado pela multiplicação dos valores de deslocamento e força

F conhecidos

$D_{k i j} \quad$ Solução fundamental para tensões

$S_{k i j} \quad$ Solução fundamental para tensões

$\mu \quad$ Coeficiente de atrito (Capitúlo 5 )

$F_{n} \quad$ Força Normal

a Raio de contato

$A_{c} \quad$ Área de contato

$w \quad$ Penetração a partir da configuração indeformada 


\section{SUMÁRIO}

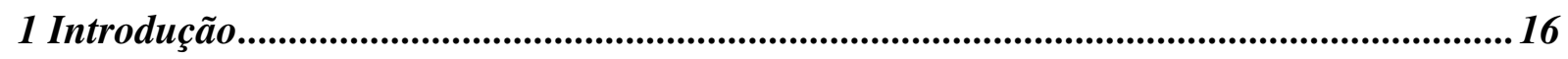

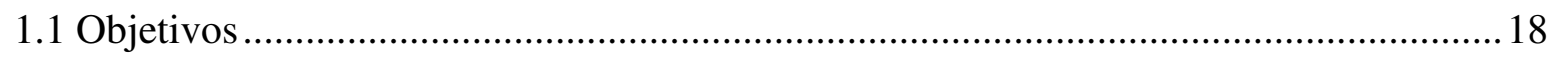

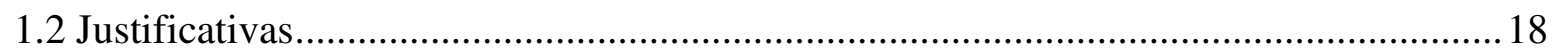

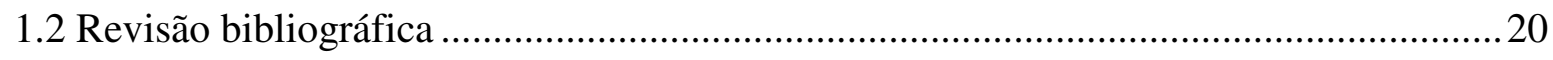

2 Conceitos básicos da escavação com TBM..........................................................................24

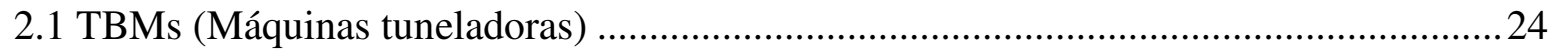

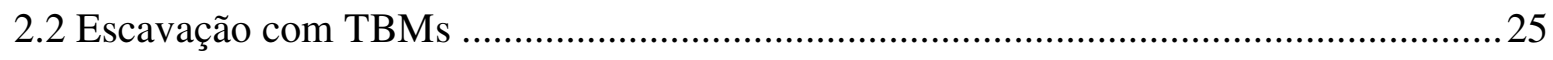

3 Conceitos fundamentais ....................................................................................................29

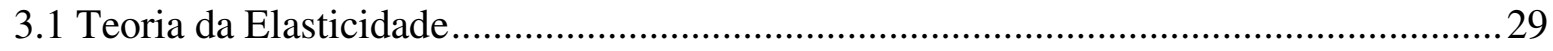

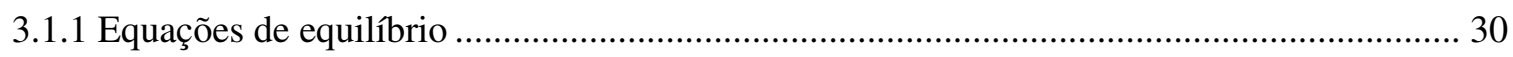

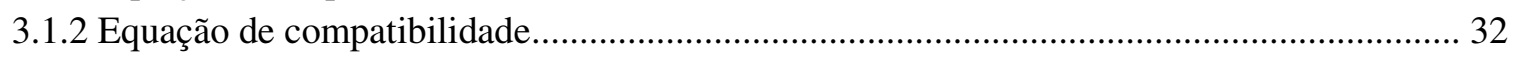

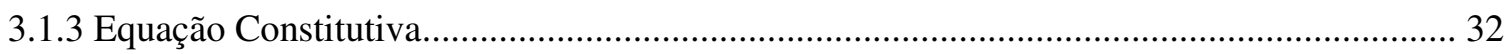

3.1.4 Equação de Navier …………………………………………………………………. 33

4 Método dos Elementos de Contorno .........................................................................................34

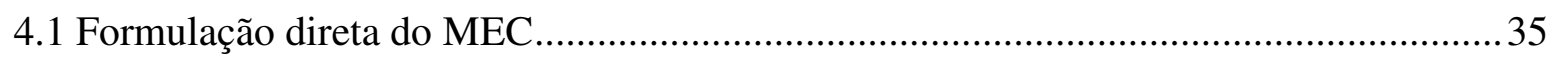

4.2 Múltiplos domínios ..................................................................................................

5 Mecânica do contato com o MEC .......................................................................................41

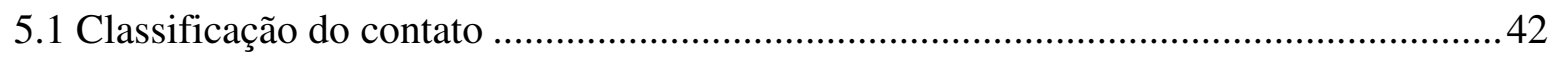

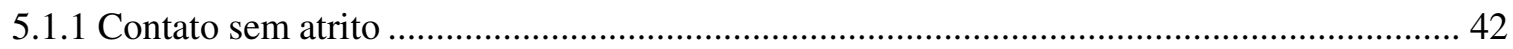

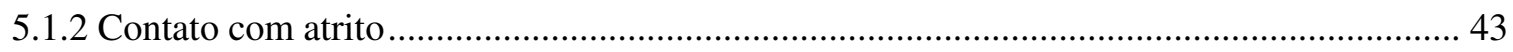

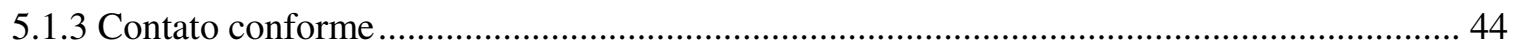

5.1.4 Contato não-conforme ……………………………………………………………… 44

5.2 Algoritmo proposto de contato com o MEC ………………......................................... 45

5.2.1 Modo de contato 1 (separação) ………………………………………………………… 46

5.2.2 Modo de contato 2 (sem deslizamento) ......................................................................... 47

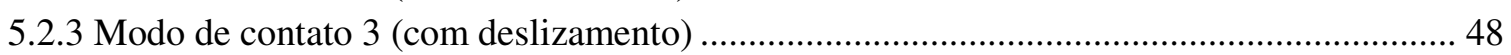

5.2.4 Estratégia de modelagem ........................................................................................... 48

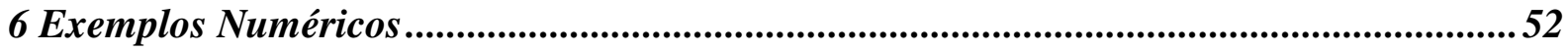

6.1 Cilindro em fundação elástica.......................................................................................53

6.2 Exemplo 2 - Pilar em uma fundação elástica..................................................................56

6.3 Exemplo 3 - Discos de corte em rocha elástica...............................................................60

7 Considerações Finais ...........................................................................................................64

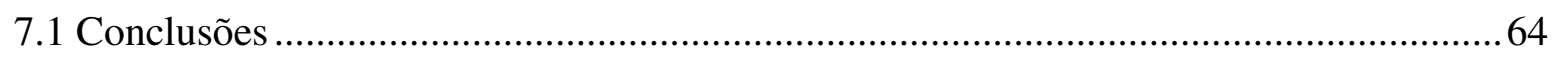




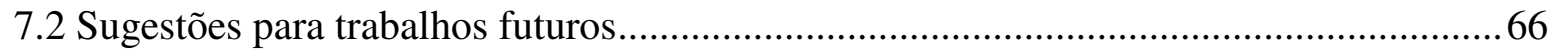

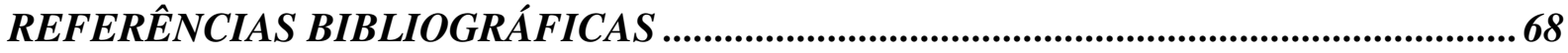




\section{Introdução}

\section{Capítulo}

Diversos problemas físicos do mundo real envolvem algum tipo de contato mecânico. $\mathrm{Na}$ engenharia, os mecanismos de contato são comuns em diversos casos, como por exemplo, na fabricação de peças estruturais ou na transferência de carregamento entre estruturas ou sólidos em geral.

Em alguns casos, a mecânica do contato é aplicada quando se deseja estudar previamente os efeitos causados em situações acidentais ou indesejadas que envolvem dois ou mais corpos, como em testes de colisão de veículos ou em estudos de balística. Há também situações em que os efeitos causados por alguma ação de contato sejam desejáveis por serem fundamentais para o funcionamento do processo, como por exemplo, em sistemas de freios para carros, na fabricação de peças metálicas por conformação mecânica ou em escavações de túneis.

Em escavações de túneis com máquinas tuneladoras, o processo de perfuração acontece por meio da aplicação de carregamentos oriundos da máquina contra o maciço rochoso. Este mecanismo de transferência de carga envolve conceitos da mecânica do contato e será detalhado ao longo do trabalho.

Os problemas da mecânica do contato podem ser estudados experimentalmente, numericamente ou a partir de modelos teóricos, em conjunto ou de forma isolada. Em geral, os ensaios experimentais exigem um custo operacional elevado ou apresentam dificuldades práticas para serem executados, principalmente pelo tempo necessário para montagem do experimento e para que sejam efetuados todos os ensaios.

Uma das vantagens da simulação numérica é a possibilidade de se obter uma série de parâmetros a um baixo custo operacional. Ainda assim, este tipo de análise não descarta os 
investigações experimentais, porém pode reduzir o número de ensaios a serem realizados e os dados obtidos nestes ensaios podem ser utilizados para aferição e validação dos modelos e procedimentos de análise numérica.

Antigamente, devido à natureza não-linear da mecânica do contato, muitos problemas eram aproximados por simplificações consideradas na concepção do projeto. Devido ao grande aumento na capacidade dos computadores, hoje podemos aplicar ferramentas da mecânica computacional para simular numericamente aplicações que incluem mecanismos de contato. Isto pode ser feito com uma precisão suficiente para fins de projeto (WRIGGERS, 2006).

Em busca de modelos matemáticos que possam representar os meios físicos de forma apropriada e satisfatória, muitos problemas da engenharia são caracterizados por equações diferenciais ou integrais. Por este motivo, apenas um número restrito de casos pode ser resolvido analiticamente. Desta maneira, o uso de ferramentas numéricas e computacionais torna-se indispensável para resolução de problemas mais complexos.

Dentre os métodos numéricos mais utilizados, destacam-se o Método dos Elementos Finitos (MEF), o Método das Diferenças Finitas (MDF) e o Método dos Elementos de Contorno (MEC).

Do ponto de vista numérico, pode-se dizer que para problemas de contato é preferível um método de contorno a um método de domínio, visto que o contato ocorre na superfície. Desta maneira, o MEC se adapta de forma mais simples para problemas deste tipo. Além disso, em uma análise por elementos de contorno, tanto os deslocamentos quanto as forças de superfície são obtidas como parte da solução e com o mesmo grau de precisão (MAN, 1994).

Devido ao crescente avanço no desenvolvimento de tecnologias e pesquisas com o MEC e suas aplicações em propósitos práticos, tem surgido também uma grande necessidade de se ter programas bem mais didáticos e com alto nível de usabilidade e extensibilidade (PEREIRA, 2004).

O autor desenvolveu ao longo deste trabalho duas produções científicas como autor principal e uma como co-autor (SAMPAIO; OLIVEIRA; NORONHA, 2008; SAMPAIO; NORONHA, 2009; OLIVEIRA;SAMPAIO; NORONHA, 2008). 


\subsection{Objetivos}

O objetivo geral deste trabalho é o estudo de problemas de contato com o MEC aplicados na análise dos discos de corte de máquinas tuneladoras.

Os principais objetivos deste trabalho são:

- Implementar computacionalmente um algoritmo para problemas bidimensionais de contato com o MEC utilizando Programação Orientada a Objetos (POO);

- Aplicar o algoritmo em simulações computacionais da interação entre máquinas tuneladoras (TBMs - Tunnel Boring Machines) e maciços rochosos;

- Realizar comparações com resultados experimentais e numéricos disponíveis na literatura e com outros métodos numéricos;

- Integrar com os outros trabalhos de pesquisa coordenados pelo Prof. Marcos Noronha e que estão diretamente envolvidos com este trabalho;

- Divulgar os resultados obtidos através de publicações de artigos e apresentação da pesquisa em congressos nacionais e internacionais.

\subsection{Justificativas}

O domínio da tecnologia de construção de túneis é um aspecto de importância estratégica para o desenvolvimento da infra-estrutura básica de cidades e estados. Além dos grandes benefícios do encurtamento de distâncias e do uso racional do espaço subterrâneo, obras de túneis geram o menor impacto ambiental possível. Trata-se assim de uma tecnologia fundamental, ambientalmente limpa e com uma baixa relação custo/benefício. 
A escavação de túneis em rocha com máquinas tuneladoras (TBMs) envolve efeitos estudados pela mecânica do contato. $\mathrm{O}$ entendimento dos problemas de contato associados ao suporte e avanço destas máquinas é essencial para as etapas de dimensionamento e verificação de projetos de túneis.

Atualmente, os métodos numéricos disponíveis representam uma das melhores ferramentas disponíveis para realizar análise de problemas de contato em túneis. Porém, uma das maiores dificuldades encontradas por tais métodos numéricos é a geração dos modelos e suas discretizações. Problemas deste tipo ocorrem, por exemplo, com o MEF, pois por ser um método de domínio todo o domínio do modelo precisa ser discretizado. Em virtude disso, o MEC torna-se mais vantajoso, pois os modelos discretizados são bem mais simples que os utilizados por outros métodos. Porém, há ainda deficiências na utilização do MEC nos processos de visualização e análises não-lineares. Em contrapartida, o desenvolvimento proposto é baseado numa nova abordagem do MEC que elimina as células de domínio.

Esta técnica que não utiliza células de domínio foi utilizada pelo grupo de pesquisa do Prof. Marcos Noronha na EPUSP para diversas aplicações do MEC e incorporados a um programa computacional que vem sendo desenvolvido desde 2004 (OLIVEIRA; SAMPAIO; NORONHA, 2008). Contudo, este é o primeiro trabalho envolvendo a mecânica do contato aplicando esta nova abordagem. Desta forma, o presente desenvolvimento está relacionado com os seguintes trabalhos realizados sob a orientação do Prof. Noronha:

- Um novo algoritmo para análises não-lineares utilizando o Método dos Elementos de Contorno; Mestrado, André Sarkis Muller (MULLER, 2004);

- Desenvolvimento de um novo algoritmo para análise viscoplástica com o Método dos Elementos de Contorno; Mestrado, Nicolas Carbone (CARBONE, 2007);

- Avanços na visualização, análise não-linear e programação com o método dos elementos de contorno; Mestrado, André M. B. Pereira (PEREIRA, 2004);

- Análise de alta precisão em modelos tridimensionais de elementos de contorno utilizando técnicas avançadas de integração numérica; Mestrado, Calebe P. G. de Souza (SOUZA, 2007), 
e alguns trabalhos que ainda estão em desenvolvimento, como

- Modelagem do Suporte de Túneis com Comportamento Viscoelástico Usando Método dos Elementos de Contorno; Mestrado, Társis R. S. T. Oliveira;

- Desenvolvimento de um novo algoritmo para modelagem de mecânica da fratura em problemas geotécnicos usando o método dos elementos de contorno; Mestrado, Marina R. P. Portela Nunes.

A implementação do algoritmo proposto, para a mecânica do contato utilizando o MEC, na plataforma computacional que vem sendo desenvolvida irá favorecer o desenvolvimento de novas pesquisas e avanços no estudo da interação da TBM com o maciço rochoso.

\subsection{Revisão bibliográfica}

Estima-se que um dos primeiros túneis foi escavado no ano de 500a.c, na ilha de Samos, pertencente à Grécia. Kolymbas (2005) faz uma descrição sucinta dos mais antigos e dos mais importantes túneis já escavados. O seu trabalho apresenta os principais conceitos relacionados com a escavação de túneis, incluindo estudos estatísticos, instalações, suporte, métodos construtivos, etc. Barton (2000) e Kolymbas (2005) apresentam em seus trabalhos detalhes sobre a escavação e as diferentes classificações das TBMs, sendo o método construtivo que utiliza estes equipamentos um dos principais aplicados em obras de escavação de túneis nos dias de hoje.

Zhao (2006) mostra que a partir dos anos 50 iniciou-se o avanço no desenvolvimento das TBMs modernas. $\mathrm{O}$ estudo da tecnologia e de seus materiais permitiu que estas máquinas pudessem ser utilizadas para escavar túneis nas mais variadas condições de terreno. Como conseqüência, verificou-se ao longo dos anos uma grande demanda por métodos consistentes 
para o projeto e construção de obras de túneis. No final do século XIX e início do século XX, realizaram-se vários esforços para estabelecer os fundamentos da Mecânica dos Túneis, através da investigação da distribuição de tensões e dos deslocamentos ocasionados por estas obras. Também foram propostos vários critérios de projeto e de dimensionamento de estruturas de suporte.

Segundo Celestino (2006), no Brasil o uso destes equipamentos de escavação iniciouse no ano de 1968 com a construção da rede metroviária das cidades de São Paulo e Rio de Janeiro.

Embora as simulações de escavação e das estruturas de suporte de túneis sejam tópicos bem discutidos, alguns pesquisadores, como Zhao (2006) e Bowerman (1993), citam em seus trabalhos que os estudos numéricos sobre maquinas tuneladoras (TBMs) ainda encontram-se em fase inicial. Há, portanto, uma grande área para realização de pesquisas e desenvolvimentos para aprimorar o processo de perfuração das TBMs. É justamente na modelagem da escavação em rocha com máquinas tuneladoras o foco principal deste trabalho.

De acordo com Beer, Duenser e Noronha (2003a; 2003b; 2003c), a revolução da informática gerou um forte impacto na engenharia de túneis, oferecendo métodos numéricos avançados para o cálculo e projeto dessas obras. Com isso, as ferramentas numéricas passaram a ser mais utilizadas em análises de escavações de túneis.

O mecanismo de indentação, penetração dos discos na rocha, é de fundamental importância para o processo de escavação com TBMs. Dentre os trabalhos envolvendo análise numérica de indentadores pode-se citar Chiaia (2000), que estudou o mecanismo de fraturamento de materiais frágeis causado pela penetração de indentadores; e Liu, Kou, Lindqvist e Tang (2002), que apresentaram simulações numéricas baseadas no MEF para o estudo do processo de fragmentação causado pela penetração de indentadores.

Segundo Venturini, na década de 80, apesar da larga utilização do MEF, o MEC já vinha ganhando destaque entre a comunidade da engenharia geotécnica, pois se apresenta como uma alternativa importante contra os gargalos da geração e necessidade de truncamento da malha para o MEF. A modelagem com o MEC é mais simples, quando comparada com a do MEF, já que apenas o contorno do modelo precisa ser discretizado. Esta característica é especialmente vantajosa no caso de modelos tridimensionais com domínio infinito. Além disto, o MEC apresenta resultados com excelente precisão para simulações dinâmicas, 
problemas com altos gradientes de tensão e potencial e para simulações de mecânica da fratura.

Diversos trabalhos referentes ao MEC vêm sendo desenvolvidos ao longo das últimas duas décadas. Em Brebbia, Telles e Wrobel (1984) e Becker (1992), pode-se encontrar uma revisão histórica bastante detalhada dos desenvolvimentos obtidos com MEC, além de uma descrição completa das suas vantagens e dos mais variados tipos de problemas em que este método pode ser aplicado.

Um trabalho recente sobre técnicas de visualização com o MEC foi apresentado por Pereira (2003) e Pereira e Noronha (2009). Os autores apresentam propostas para representação dos resultados no domínio superando os obstáculos apresentados na visualização com o MEC, com preservação da propriedade básica do MEC, que é a discretização somente do contorno do modelo.

Muller (2004) utilizou a técnica de visualização proposta por Pereira (2003) em um novo algoritmo para análises elastoplásticas com o MEC. Ainda fazendo o uso da referida técnica de visualização, Carbone (2007) estendeu o uso desta técnica para análises viscoplásticas com o MEC.

Formulações para análise de problemas de contato usando o MEC para problemas bidimensionais podem ser encontradas em Man (1994) e Becker (1992). Tais formulações baseiam-se no uso da técnica aplicada nó-a-nó com a inserção explícita das equações de contato. Além disso, MAN apresentou técnicas otimizadas para a resolução das matrizes acopladas do sistema.

O trabalho de Dandekar e Conant (1992) contribuiu para a compreensão da conformidade de malhas em problemas de contato com o MEC. A discretização não-conforme foi estudada por Blazquez et al. (1992), Huesman e Kuhn (1995) e Olukoko e Becker (1993).

Apesar de ter sido introduzida há mais de 40 anos, uma abordagem recente no campo do desenvolvimento de códigos computacionais é a Programação Orientada a Objetos (POO). $\mathrm{Na}$ engenharia e no campo científico em geral, este novo paradigma tem sido amplamente aplicado devido ao benefício do mesmo em reaproveitamento de códigos. O uso da POO em aplicações com o MEC ainda é um tema incipiente. Mackerle (2000, 2004) publicou dois artigos interessantes cujo objetivo foi apresentar as principais publicações entre os anos de 1990 e 2003 relacionadas com uso da POO em programas destinados ao MEC e MEF. 
Jones et al. (2001) sugeriu uma técnica de implementação eficiente com o uso de POO para um programa aplicado ao MEC. Lage (1998) apresentou o projeto de uma biblioteca de classes aplicável no desenvolvimento de sistemas computacionais para elementos de contorno. Lee e Tan (1990, 1993) escreveram sobre a programação adaptativa: teoria, implementação e aplicações. Noronha (1998) apresentou um desenvolvimento de uma primeira versão de um algoitmo baseado em POO para o MEC. Posteriormente, o grupo de pesquisas do Prof. Noronha realizou avanços nesse código através da incorporação de técnicas avançadas e mais modernas, como os Padrões de Projeto (Noronha, Muller e Pereira, 2005). 


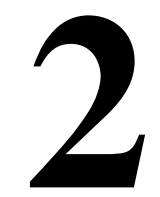

\section{Conceitos Básicos da Escavação com TBMs}

\section{Capítulo}

Neste capítulo descreve-se sucintamente o processo de escavação de túneis por máquinas tuneladoras (Tunnel Boring Machines - TBMs) com ênfase no mecanismo de quebra da rocha devido à ação dos discos de corte dessas máquinas.

\subsection{TBMs (Máquinas tuneladoras)}

O termo TBM origina-se da expressão em inglês "Tunnel Boring Machine", que em português significa "Máquina de Perfuração de Túneis", que também se refere a máquinas tuneladoras.

A TBM é um equipamento utilizado para escavar túneis sem o uso de explosivos ou ações de impacto, podendo escavar em diversos tipos de material, desde rochas duras até terrenos arenosos.

$\mathrm{Na}$ extremidade de uma TBM existe um grande disco giratório (cabeça de corte) que contém pequenos discos de corte que servem para aplicar o carregamento contra o maciço, de forma que as arestas dos discos entrem em contato com a rocha. A Figura 2.1 ilustra os discos e a cabeça de corte de uma TBM. 
Em geral, a sustentação longitudinal de uma TBM é feita por sapatas de fixação (Figura 2.1). Elas impedem o movimento naquela direção servindo de suporte para que a máquina aplique o carregamento necessário para uma boa condição de escavação.

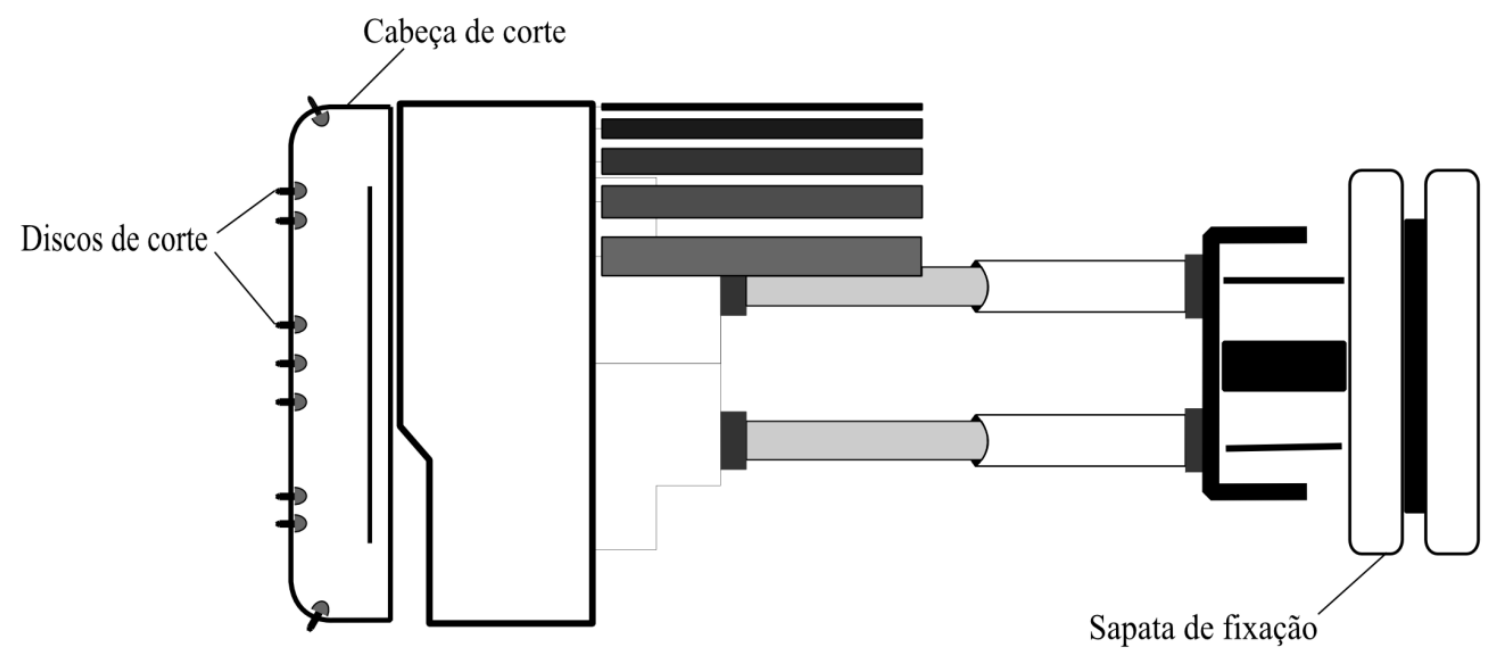

Figura 2.1 - Esquematização da TBM: discos de corte, cabeça de corte e sapata de fixação.

\subsection{Escavação com TBMs}

A escavação é realizada à medida que a máquina pressiona o maciço ao mesmo tempo em que a sua cabeça de corte gira. O contato acontece entre os discos de corte (que são responsáveis pela quebra da rocha) e a frente de escavação.

A perfuração de um túnel envolve um processo contínuo de fissuração e fragmentação da rocha. Este processo pode ser dividido em duas partes: entalhamento (ou indentação) e despedaçamento (ZHAO, 2006). No entalhamento ocorre a penetração dos discos de corte, resultando no esmagamento da rocha e criando uma zona de tensão onde as fissuras se propagam em todas as direções. O despedaçamento acontece à medida que estas fissuras 
atingem a superfície livre ou encontram outras rachaduras causadas por cortadores vizinhos, formando os fragmentos e, conseqüentemente, prossegue-se a escavação (Figura 2.2).

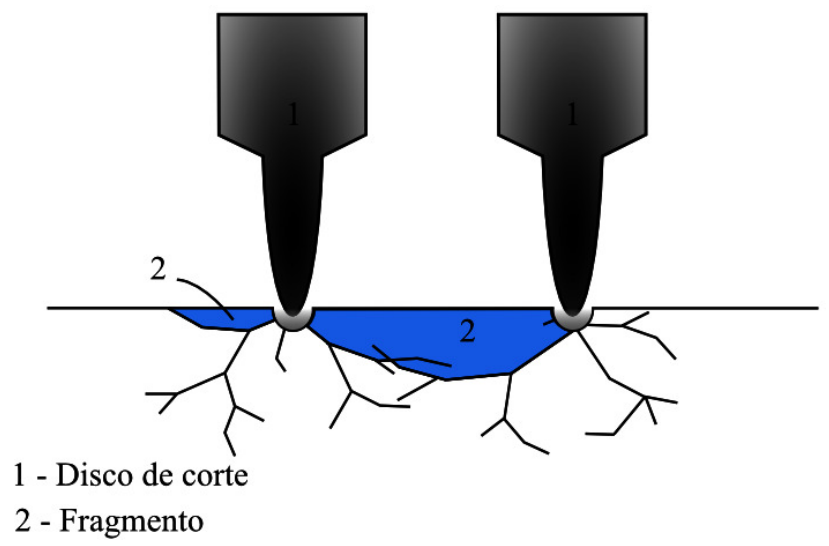

Figura 2.2 - Representação da fragmentação causada pelos discos de corte.

A função das sapatas de fixação é imobilizar o corpo central da TBM, servindo como suporte para que a cabeça de corte aplique a força necessária para a fissuração com os discos de corte. Assim, a tensão aplicada pelas sapatas de fixação depende da força a ser desenvolvida na cabeça de corte junto ao maciço. Esta força não deve gerar instabilidades no túnel.

Numa escavação com TBMs, podem ocorrer distúrbios nas paredes do túnel devido à ação das sapatas de fixação, principalmente por fissurações excessivas ou em zonas que tendem a ser instáveis. A Figura 2.3 ilustra a ação das sapatas de fixação contra as paredes do túnel (BARTON, 2000).

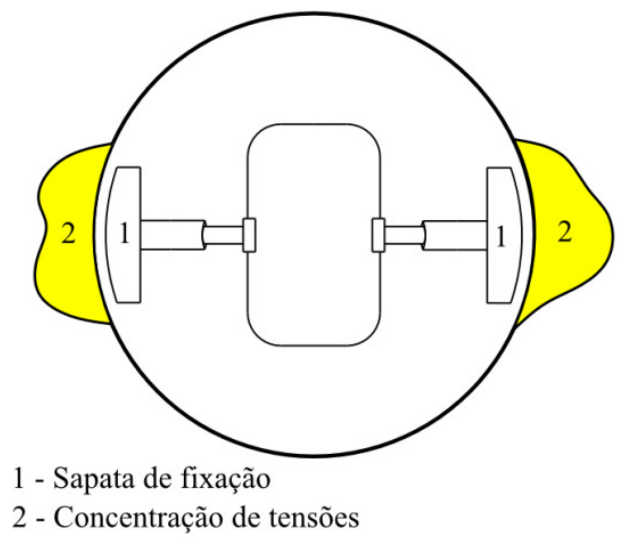

Figura 2.3 - Concentração de tensões causadas pelas sapatas de fixação. 
A eficiência da escavação depende de fatores como: o espaçamento entre os discos de corte, a velocidade de giro da cabeça de corte, o ângulo de ataque, a geometria e a pressão exercida pelos cortadores e as características da rocha (CIGLA; YAGIZ; OZDEMIR, 2001; ZHAO, 2006).

A escavação em materiais rochosos é influenciada pelas características do maciço. O comportamento da rocha submetida aos cortadores depende das propriedades da rocha e das condições naturais que ela se encontra. Em rochas foliadas, por exemplo, quando a máquina avança paralelamente aos planos de foliação, a quebra da rocha é dificultada devido ao efeito que as foliações causam na propagação das fissuras e, conseqüentemente, na formação dos fragmentos. Em outra situação, quando a foliação é perpendicular ao eixo do túnel, tem-se geralmente a melhor condição para a formação dos fragmentos e, portanto, uma boa taxa de penetração (CIGLA; YAGIZ; OZDEMIR, 2001). Assim, os parâmetros do maciço a serem estudados para uma escavação com TBM devem ser baseados nas características de resistência e fragilidade da rocha e no espaçamento e orientação das juntas (ZHAO, 2006).

Conforme foi mencionado, a maior parte da transferência de energia de uma TBM para o maciço é feita através dos discos de corte. Portanto, estudar a geometria e as características do material dessas peças é de grande importância para que a transmissão de esforços possa ser entendida e otimizada.

Há duas décadas, o perfil dos cortadores das TBMs eram em forma de "V" (Figura 2.4a). Estes discos de corte são bastante eficientes enquanto novos. Porém, com o desgaste natural durante a escavação, a área de contato se torna cada vez maior e, com isso, o avanço da máquina diminui rapidamente (KOLYMBAS, 2005). Para melhorar o desempenho dos cortadores, estes discos foram substituídos por outros discos denominados discos de seção constante (Figura 2.4b), nos quais o desgaste natural não afeta tão rapidamente a eficiência da escavação (CIGLA; YAGIZ; OZDEMIR, 2001). 


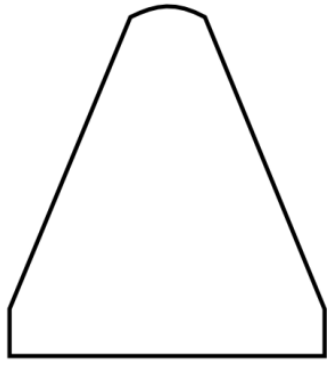

(a)

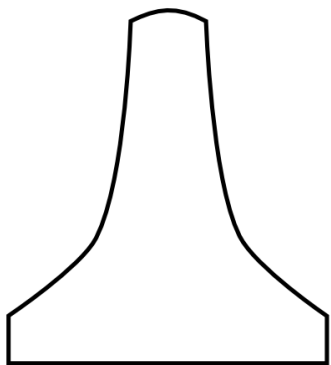

(b)

Figura 2.4 - Formatos de discos de corte. (a) disco em forma de "V". (b) disco de seção constante.

O diâmetro também influencia no desempenho dos cortadores. Para um mesmo carregamento, discos maiores resultam em profundidades de penetração menores, pois a área de contato aumenta com o aumento de diâmetro. Porém, pelo mesmo motivo, o seu desgaste se torna menor, melhorando a capacidade de produção da máquina. Além disso, discos maiores giram numa velocidade menor, reduzindo o efeito causado pelo aquecimento.

Todos os fatores supracitados devem ser combinados de forma a aumentar a vida útil dos cortadores e reduzir os custos de escavação.

Além das características geométricas, a disposição dos cortadores na cabeça de corte também exerce grande influência no processo de fragmentação. Conforme já foi mencionado, a formação dos fragmentos depende da propagação das fissuras causadas por todo o conjunto de cortadores. A interação entre os discos de corte é observada à medida que fissuras originadas por discos de corte vizinhos propagam-se em direção umas das outras.

A transmissão dos efeitos de carregamento para o maciço, tanto oriundos das sapatas de fixação quanto dos discos de corte, envolvem conceitos da Mecânica do Contato e isto reforça a importância do assunto neste tipo de aplicação. 


\section{Conceitos fundamentais}

\section{Capítulo}

O objetivo deste capítulo é apresentar alguns conceitos básicos sobre a teoria da elasticidade linear. Estes assuntos são de fundamental importância para as formulações descritas nos próximos capítulos.

\subsection{Teoria da Elasticidade}

O comportamento elástico de um material é caracterizado pela ausência de deformações residuais após o material ser submetido a carregamentos e descarregamentos. $\mathrm{Ou}$ seja, em um ciclo de carga deste tipo, as curvas de tensão vs. deformação são coincidentes. Uma vez cessado o carregamento, as tensões e deformações retornam ao patamar inicial.

A teoria da elasticidade é a parte da mecânica dos sólidos que estuda os campos de tensão, deformação e deslocamento produzidos em sólidos elásticos submetidos a algum carregamento. A relação entre estes efeitos é dada por três conjuntos de equações: as equações de equilíbrio; as equações constitutivas; e as equações de compatibilidade. 


\subsubsection{Equações de equilíbrio}

Considere-se um sólido de material elástico submetido a um carregamento externo e em equilíbrio, conforme ilustrado na Figura 3.1, onde $S_{v}$ são as forças de superfície, $S_{u}$ os deslocamentos na superfície e $b$ as forças de volume.

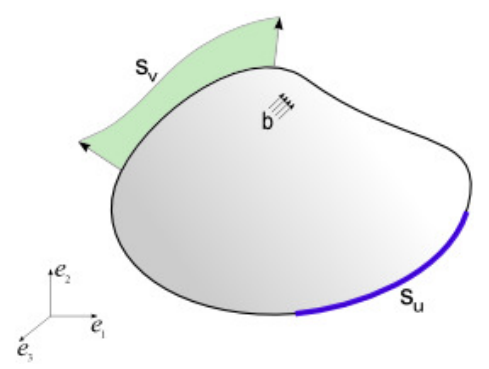

Figura 3.1 - Sólido em equilíbrio submetido a deslocamentos e forças prescritas.

Em um elemento infinitesimal cúbico que represente um ponto $P$ qualquer deste sólido, tem-se que as tensões atuantes em suas faces são representadas por um conjunto de componentes de tensão conforme ilustrado na Figura 3.2.

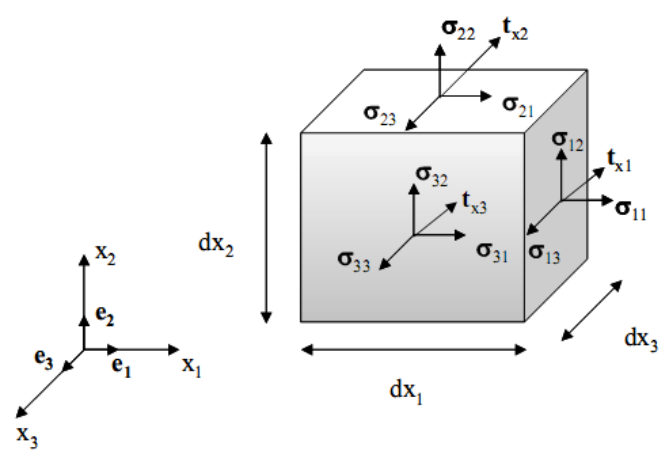

Figura 3.2 - Tensões atuantes nas faces de um elemento cúbico infinitesimal.

Com os componentes de tensão da figura 3.2, monta-se o tensor das tensões de Cauchy 


$$
[T]=\left[\begin{array}{lll}
\sigma_{11} & \sigma_{12} & \sigma_{13} \\
\sigma_{21} & \sigma_{22} & \sigma_{23} \\
\sigma_{31} & \sigma_{32} & \sigma_{33}
\end{array}\right],
$$

onde $[T]$ é simétrico, ou seja, $\sigma_{12}=\sigma_{21}, \sigma_{13}=\sigma_{31}$ e $\sigma_{23}=\sigma_{32}$.

A partir do tensor $[T]$, pode-se calcular as tensões atuantes em um ponto $P$ segundo qualquer plano.

Em um sólido sob carregamento externo, o equilíbrio em um ponto qualquer é satisfeito quando

$$
\sigma_{i j, j}+b_{i}=0
$$

A Eq. 3.2 é nomeada de equação de equilíbrio.

A força atuante em um ponto da superfície pode ser calculada a partir das tensões dada pela Eq. (3.1) desde que seja conhecido o vetor normal deste ponto. Ou seja, considere-se o tetraedro infinitesimal da Figura 3.3 cujas componentes de força atuantes na superfície inclinada são dadas por

$$
t_{i}=\sigma_{i j} n_{j},
$$

onde $n_{j}$ é o cosseno diretor, $n_{j}=\cos \left(\boldsymbol{n}, n_{j}\right)$; e $\boldsymbol{t}=t_{i} n_{i}$.

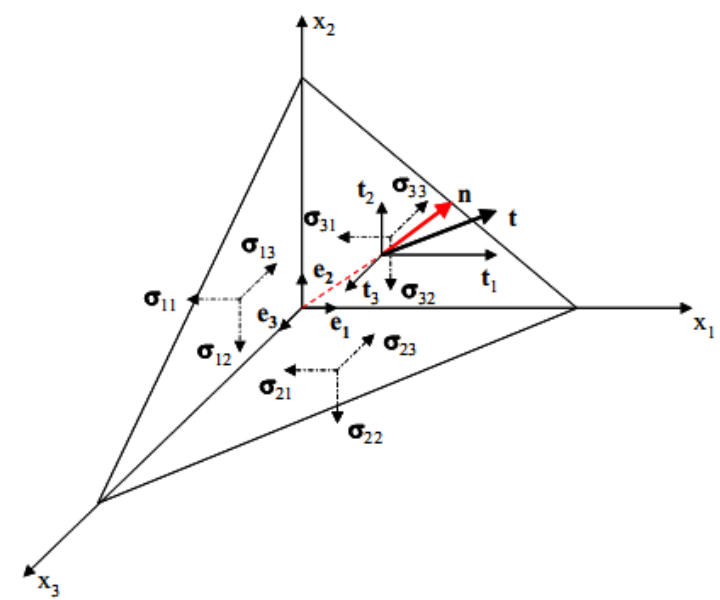

Figura 3.3 - Forças em uma superfície infinitesimal com orientação arbitrária. 


\subsubsection{Equação de compatibilidade}

As equações de compatibilidade relacionam deformações e deslocamentos e, por este motivo, muitas vezes são chamadas de relações deformação-deslocamento. Uma alteração na posição relativa entre quaisquer pontos devido a um deslocamento configura uma deformação.

O deslocamento $\boldsymbol{u}$ de um ponto $P$ do domínio $\Omega$ é representado por

$$
\boldsymbol{u}=u_{i} e_{i}
$$

Por sua vez, as relações de compatibilidade entre os deslocamentos e as deformações $\boldsymbol{\varepsilon}$ são definidas, considerando a hipótese de pequenos deslocamentos, rotações e deformações, por

$$
\varepsilon_{i j}=\frac{1}{2}\left(u_{i, j} u_{j, i}\right)
$$

O tensor $[\varepsilon]$ é simétrico e definido como o tensor das deformações. As equações independentes dadas pela Eq.(3.5) são denominadas de equações de compatibilidade.

\subsubsection{Equação Constitutiva}

As equações constitutivas estão relacionadas ao comportamento do material do sólido e também são chamadas de relações tensão-deformação por relacionar tais grandezas.

Para materiais homogêneos, lineares e isotrópicos tem-se a seguinte relação constitutiva 


$$
\sigma_{i j}=\lambda \delta_{i j} \varepsilon_{k k}+2 \mu \varepsilon_{i j}
$$

onde $\lambda$ e $\mu$ são os coeficientes de Lamé, dados por

$$
\lambda=\frac{v E}{(1+v)(1-2 v)} \quad \text { e } \quad \mu=\frac{E}{1+v}
$$

onde o coeficiente E é o módulo de elasticidade longitudinal, v é o coeficiente de Poisson, e $\delta_{i j}$ é o delta de Kronecker, definido por

$$
\delta_{i j}=\left\{\begin{array}{l}
1 \rightarrow \text { se } i=j \\
0 \rightarrow \text { se } i \neq j
\end{array} .\right.
$$

A Eq.(3.6) é chamada de lei de Hooke generalizada.

\subsubsection{Equação de Navier}

As equações apresentadas anteriormente (Eqs.(3.2), (3.5) e (3.6)) relacionam-se entre si pelos parâmetros de tensão e deformação. Desta forma, efetuando-se relações algébricas, podemos reduzi-las em uma única expressão denominada de equação de Navier, expressa por

$$
\left(\frac{1}{1-2 v}\right) u_{j, j l}+u_{l, j j}+\frac{1}{\mu} b_{l}=0
$$

A equação de Navier corresponde às equações de equilíbrio escritas em termos de deslocamentos. 


\section{Método dos Elementos de Contorno}

\section{Capítulo}

Neste capítulo será apresentada uma formulação do MEC para problemas da elasticidade linear. Ao final do capítulo, será feita uma breve descrição do MEC para problemas envolvendo múltiplos domínios.

A idéia básica do MEC é representar o comportamento de um corpo através de sua superfície, reduzindo a dimensionalidade do problema em uma dimensão. Esta propriedade tem como vantagem a redução dos sistemas a serem resolvidos numericamente, além de facilitar a criação das malhas discretizadas do modelo (HUNTER, 2001).

Em geral, a formulação do MEC para problemas da elasticidade pode ser feita de três formas diferentes: o método direto, o indireto e o semi-indireto. O método direto utiliza parâmetros com significado físico, como deslocamentos e forças; nos demais as formulações são feitas a partir de funções de densidade fictícias ou funções de tensões (BECKER, 1992). Por se tratar de um estudo de aplicação em engenharia, o método direto é o mais adequado para os propósitos deste trabalho. 


\subsection{Formulação direta do MEC}

Pela formulação direta são consideradas incógnitas as forças e os deslocamentos no contorno. O ponto de partida é a solução da equação diferencial de equilíbrio utilizando uma função de ponderação especial, que adiante será chamada de solução fundamental.

Inicialmente, considera-se um corpo sólido de material homogêneo representado por um domínio $\Omega$ que é delimitado por um contorno $\Gamma$. Em cada ponto do contorno é conhecido o deslocamento ou a força de superfície, que formam as condições de contorno. Estas condições de contorno estão divididas em

$$
\begin{gathered}
u_{k}=\bar{u}_{k} \mathrm{em} \Gamma_{1} e \\
p_{k}=\sigma_{k j} n_{j}=\bar{p}_{k} \mathrm{em} \Gamma_{2},
\end{gathered}
$$

de forma que $\Gamma=\Gamma_{1}+\Gamma_{2}$. As condições de contorno em deslocamento são chamadas de essenciais, enquanto a condição de contorno em força é chamada de natural.

Seja um sólido que satisfaz a equação diferencial de equilíbrio da teoria da elasticidade, satisfazendo a Eq.(3.2). Aplicando-se a solução fundamental $u^{*}$ como uma função de ponderação deve-se ter

$$
\int_{\Omega}\left(\sigma_{k j, j}+b_{k}\right) u_{k}^{*} d \Omega=0
$$

Esta integral no domínio pode ser levada para o contorno ao serem efetuadas duas integrações por partes e aplicando o teorema do divergente onde for necessário. Além disso, aplicam-se os conceitos da teoria da elasticidade apresentados no capítulo 3 e considera-se que a solução fundamental é o resultado em deslocamento para um carregamento dado por uma função do tipo delta de Dirac. Como resultado, obtém-se a seguinte equação integral

$$
u_{l}^{i}=\int_{\Gamma} p_{k} u_{l k}^{*} d \Gamma-\int_{\Gamma} u_{k} p_{l k}^{*} d \Gamma+\int_{\Omega} b_{k} u_{l k}^{*} d \Omega
$$


A Eq.(4.3) é chamada de Identidade de Somigliana e fornece as componentes de deslocamento em qualquer ponto interno do domínio. As componentes $u_{l k}^{*}$ e $p_{l k}^{*}$ (soluções fundamentais) representam o deslocamento e a força de superfície, respectivamente, na direção $k$, gerados por uma força unitária aplicada em $i$ na direção $l$. Estas duas grandezas são expressas por

$$
u_{l k}^{*}=\frac{1}{8 \pi \mu(1-v)}\left[(3-4 v) \ln \left(\frac{1}{r}\right) \delta_{l k}+r,_{l} r_{, k}\right]
$$

e

$$
p_{l k}^{*}=-\frac{1}{4 \pi(1-v) r}\left\{\frac{\partial r}{\partial n}\left[(1-2 v) \delta_{l k}+2 r, r_{l},,_{k}\right]+(1-2 v)\left(n_{l} r,_{k}-n_{k} r,_{l}\right)\right\}
$$

onde $r$ é a distância entre o ponto em que $u_{l k}^{*}$ e $p_{l k}^{*}$ são observados e o ponto em que a força unitária é aplicada; e $\boldsymbol{n}$ é o vetor normal no ponto onde a força de superfície $p_{l k}^{*}$ é medida.

Embora as forças de volume, $b_{k}$, na Eq.(4.3) estejam definidas em uma integral de domínio, a equação é classificada como uma equação integral de contorno visto que estas forças são conhecidas e não adicionam nenhuma incógnita ao sistema de equações (HUNTER, 2001). Além disso, há técnicas simples de solução para este tipo de situação (BANERJEE; PAPE, 1987), que consideram a influência das forças de volume sem o uso de integrais de domínio. Por este motivo, a partir de agora, as integrais que contém as forças de volume não aparecerão mais nas equações.

Através da Identidade de Somigliana e com os valores de $u_{k}$ e $p_{k}$ conhecidos em todo o contorno, podemos calcular o deslocamento em qualquer ponto do domínio. Entretanto, um problema de singularidade acontece quando precisamos calcular estes valores no contorno, isto ocorre porque $r$ tende a zero nestes pontos. Este problema é solucionado aproximando-se o contorno naquele ponto por uma semi-esfera de raio $\varepsilon \rightarrow 0$ (BREBBIA; DOMINGUES,1989). Assim, tal condição singular é eliminada e a Eq.(4.3) resulta em

$$
c_{l k}^{i} u_{k}^{i}=\int_{\Gamma} p_{k} u_{l k}^{*} d \Gamma-\int_{\Gamma} u_{k} p_{l k}^{*} d \Gamma
$$

onde o coeficiente $c^{i}$ depende da geometria do contorno na vizinhança do nó $i$. 
A equação (4.6) é o ponto de partida para o MEC propriamente dito. Ela é usada para montar o sistema de equações que irá determinar os valores de contorno desconhecidos.

O MEC basicamente aproxima a superfície do sólido por uma série de elementos em seu contorno, chamados de elementos de contorno. Os deslocamentos e forças de superfície são representados em termos de valores nodais e estendidos para o restante do contorno utilizando-se funções de interpolação definidas para cada elemento. Assim, em cada elemento os deslocamentos e forças de superfície ficam determinados por

$$
\boldsymbol{u}=\boldsymbol{\Phi}_{\mathrm{j}} \mathbf{u}^{\mathrm{j}} \quad \text { e } \quad \mathbf{p}=\boldsymbol{\Phi}_{\mathrm{j}} \mathbf{p}^{\mathrm{j}}
$$

onde $\boldsymbol{\Phi}_{\mathrm{j}}$ são as funções de interpolação; e $\mathbf{u}^{\mathrm{j}}$ e $\mathbf{p}^{\mathrm{j}}$ são os valores dos deslocamentos e das forças de superfície nos nós dos elementos, respectivamente.

Considerando-se a aproximação dada pela Eq.(4.7), a Eq.(4.6) pode ser escrita da seguinte forma

$$
\mathbf{c}^{\mathbf{i}} \mathbf{u}^{\mathbf{i}}+\sum_{j=1}^{N E}\left\{\int_{\Gamma_{j}} \mathbf{p}^{*} \boldsymbol{\Phi} d \Gamma\right\} \mathbf{u}^{\mathbf{j}}=\sum_{j=1}^{N E}\left\{\int_{\Gamma_{j}} \mathbf{u}^{*} \boldsymbol{\Phi} d \Gamma\right\} \mathbf{p}^{\mathbf{j}},
$$

sendo $N E$ o número de elementos de contorno.

Aplicando-se a Eq.(4.8) em cada um dos nós do contorno obtém-se o seguinte sistema de equações

$$
\mathbf{H u}=\mathbf{G p}
$$

onde $\mathbf{H}$ e $\mathbf{G}$ são matrizes densas e não-simétricas, e os vetores $\mathbf{u}$ e $\mathbf{p}$ representam os deslocamentos e forças de superfície, respectivamente.

O sistema da Eq.(4.9) pode ser simplificado passando-se as variáveis desconhecidas e as respectivas colunas das matrizes $\mathbf{H}$ e $\mathbf{G}$ para o lado esquerdo da igualdade, e as variáveis conhecidas para o lado direito. Estas últimas são formadas pelas condições de contorno do problema. Desta forma, outro sistema mais simplificado é obtido

$$
\mathbf{A x}=\mathbf{F}
$$


onde o vetor $\mathbf{x}$ contém os coeficientes desconhecidos de $\mathbf{u}$ e $\mathbf{p}$, e $\mathbf{F}$ é o vetor formado pela multiplicação dos valores de deslocamento e força conhecidos com as respectivas colunas das matrizes $\mathbf{H}$ e $\mathbf{G}$.

Uma vez que o sistema da Eq.(4.10) esteja resolvido o deslocamento em qualquer ponto do domínio pode ser calculado utilizando-se a Identidade de Somigliana, Eq.(4.3). O tensor das tensões é calculado de forma similar aplicando-se as relações discutidas no capítulo 3 , resultando em

$$
\sigma_{i j}=\int_{\Gamma} D_{k i j} p_{k} d \Gamma-\int_{\Gamma} S_{k i j} u_{k} d \Gamma
$$

onde

$$
D_{k i j}=\frac{1}{4 \pi(1-v) r}\left\{(1-2 v)\left(\delta_{k i} r,{ }_{j}+\delta_{k j} r,_{i}-\delta_{i j} r_{k}\right)+2 r,{ }_{i} r,{ }_{j} r,_{k}\right\}
$$

$\mathrm{e}$

$$
\begin{aligned}
& S_{k i j}=\frac{\mu}{2 \pi(1-v) r^{2}}\left\{2 \frac{\partial r}{\partial n}\left[(1-2 v) \delta_{i j} r{ }_{, k}+v\left(\delta_{i k} r,{ }_{j}+\delta_{j k} r{ }_{i}\right)-4 r,{ }_{i},{ }_{, j} r_{{ }_{k}}\right]+\right. \\
& \left.+2 v\left(n_{i} r,{ }_{j} r{ }_{k}+n_{j} r,_{i} r r_{k}\right)+(1-2 v)\left(2 n_{k} r,{ }_{i} r,{ }_{j}+n_{j} \delta_{i k}+n_{i} \delta_{j k}\right)-(1-4 v) n_{k} \delta_{i j}\right\}
\end{aligned}
$$

\subsection{Múltiplos domínios}

Neste item, será mostrada uma técnica do MEC para situações onde existem múltiplos domínios. Os conceitos apresentados aqui estão baseados nos trabalhos dos autores Becker (1992), Brebbia e Domingues (1989) e Gaul (2003).

Nos itens anteriores, as propriedades do material foram consideradas constantes em todo o domínio. Porém, em alguns casos torna-se necessário dividir o domínio de modo que as propriedades de cada subdomínio sejam independentes umas das outras, e que tais 
propriedades não variem dentro destas sub-regiões. Nestes casos, o problema é resolvido por meio de técnicas de subdomínios (Figura 4.2).

Em geral, a resolução de problemas deste tipo é dada a partir de manipulações e considerações adicionais no sistema da Eq.(4.9). Desta maneira, não é necessário mudar ou acrescentar novos conceitos ao método.

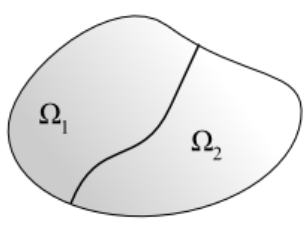

(a)

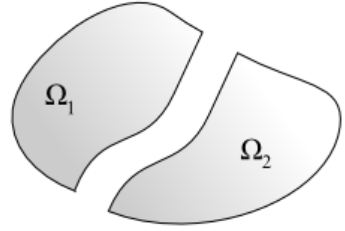

(b)

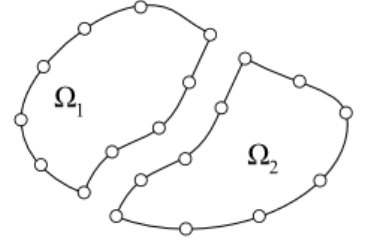

(c)

Figura 4.1 - Subdomínios (a) sólido; (b) divisão do sólido em subdomínios (c) subdomínios discretizados.

Inicialmente, as matrizes do sistema da Eq.(4.9) são calculadas separadamente para cada um dos subdomínios. Pela técnica utilizada aqui, as matrizes são acopladas formando um único sistema cuja solução é a resposta do problema.

Seja um sólido $\Omega$ dividido em dois subdomínios (como o da Figura 4.2). A partir da Eq.(4.9), separando-se os termos referentes à interface daqueles que se referem ao restante do sólido, tem-se

$$
\left[\begin{array}{ll}
\mathbf{H}_{A} & \mathbf{H}_{k}
\end{array}\right]\left[\begin{array}{l}
\mathbf{u}_{A} \\
\mathbf{u}_{k}
\end{array}\right]=\left[\begin{array}{ll}
\mathbf{G}_{A} & \mathbf{G}_{k}
\end{array}\right]\left[\begin{array}{l}
\mathbf{p}_{A} \\
\mathbf{p}_{k}
\end{array}\right]
$$

onde o sub-índice $A$ se refere aos elementos do contorno externo e o sub-índice $K$ indica a região da interface.

A compatibilidade e o equilíbrio devem ser satisfeitos nos elementos da interface, portanto

$$
\mathbf{u}_{K}^{1}=\mathbf{u}_{K}^{2}=\mathbf{u}_{K}
$$

$\mathrm{e}$

$$
\mathbf{p}_{k}^{1}=-\mathbf{p}_{k}^{2}=\mathbf{p}_{k}
$$

sendo os índices 1 e 2 referentes aos respectivos subdomínios. 
Substituindo as equações Eq.(4.16) e Eq.(4.17) na Eq.(4.15) e reordenando a Eq.(4.15), trazendo para o lado esquerdo os termos de $\mathbf{G}_{A}, \mathbf{G}_{K}$ e $\mathbf{H}_{K}$, e levando $\mathbf{H}_{A}$ para o lado direito, obtém-se

$$
\left[\begin{array}{lll}
\mathbf{G}_{A} & \mathbf{G}_{k} & -\mathbf{H}_{k}
\end{array}\right]\left[\begin{array}{l}
\mathbf{p}_{A} \\
\mathbf{p}_{k} \\
\mathbf{u}_{k}
\end{array}\right]=\left[\mathbf{H}_{A}\right]\left[\mathbf{u}_{A}\right]
$$

O acoplamento é feito aplicando-se as condições de equilíbrio e compatibilidade na Eq.(4.18). O sistema final é dado por

$$
\left[\begin{array}{cccc}
\mathbf{G}_{A}^{1} & \mathbf{G}_{K}^{1} & -\mathbf{H}_{K}^{1} & \mathbf{0} \\
\mathbf{0} & -\mathbf{G}_{K}^{2} & -\mathbf{H}_{K}^{2} & \mathbf{G}_{A}^{2}
\end{array}\right]\left[\begin{array}{l}
\mathbf{p}_{A}^{1} \\
\mathbf{p}_{\mathrm{k}} \\
\mathbf{u}_{\mathrm{k}} \\
\mathbf{p}_{A}^{2}
\end{array}\right]=\left[\begin{array}{cc}
\mathbf{H}_{A}^{1} & \mathbf{0} \\
\mathbf{0} & \mathbf{H}_{A}^{2}
\end{array}\right]\left[\begin{array}{l}
\mathbf{u}_{A}^{1} \\
\mathbf{u}_{A}^{2}
\end{array}\right]
$$

A solução da Eq.(4.19) contém os valores das incógnitas de força e deslocamento na superfície e na interface. 


\section{Mecânica do contato com o MEC}

\section{Capítulo}

O objetivo deste capítulo é descrever uma formulação do MEC para solução de problemas da mecânica do contato. Tal solução é baseada nas formulações apresentadas por (BECKER, 1992; MAN, 1994).

Nos desenvolvimentos a seguir, consideram-se as equações integrais clássicas do MEC descritas no Capítulo 4. Na parte inicial são feitas algumas colocações inerentes ao estudo do contato.

Os problemas de contato envolvem uma série de fatores que, isoladamente ou não, influenciam na resposta do problema, podendo torná-lo extremamente complexo. Fatores como a rugosidade, a variação de temperatura do meio ou resultante de alguma ação mecânica, os parâmetros individuais do material (ex.: fragilidade, plasticidade etc.), e a mudança de sua geometria no decorrer do processo são alguns exemplos que ilustram a diversidade de efeitos que podem ser considerados nos problemas da mecânica do contato.

O objetivo deste trabalho, entretanto, é desenvolver um algoritmo adaptado para problemas da elasticidade linear, desconsiderando os fatores não-relacionados com esta teoria.

Uma vez que a superfície de contato não seja conhecida a priori, o estudo de problemas de contato envolve, em seus modelos matemáticos, hipóteses que definirão o comportamento da superfície de contato ao longo do carregamento (FISCHER-CRIPS, 2006). O número de considerações depende do tipo de problema a ser analisado, visando uma representação mais realista do problema. 


\subsection{Classificação do contato}

\subsubsection{Contato sem atrito}

Em um contato sem atrito, os sólidos podem deslizar uns sobre os outros sem que haja resistência na direção tangencial à superfície de contato. Portanto, o efeito do carregamento externo na interface de contato será somente de compressão normal. Sem atrito, a força tangencial será sempre igual à zero (Fig. 5.1b).

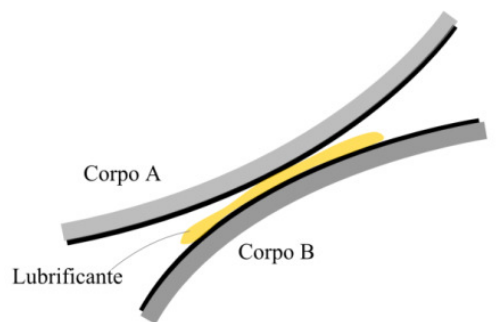

(a)

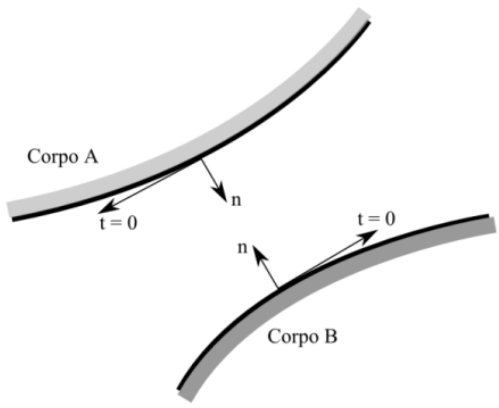

(b)

Figura 5.1 - Contato sem atrito. (a) contato com lubrificante. (b) forças na superfície de contato.

A aplicação prática deste tipo de contato é relativamente limitada. Em geral, este tipo de consideração é feito nos problemas envolvendo superfícies lisas e bem lubrificadas (Fig. 5.1a) (MAN, 1994). 


\subsubsection{Contato com atrito}

Ao ser considerado o efeito de atrito, duas situações podem ocorrer: contato sem deslizamento tangencial (stick); e, contato com deslizamento tangencial (slip).

$\mathrm{Na}$ primeira situação, stick, o deslizamento é impedido pela força de atrito desenvolvida na superfície. A força de atrito é a componente de resistência tangencial nos pontos de contato da superfície. Em outras palavras, quando houver stick, a componente tangencial que atua entre os sólidos é menor que o limite de atrito. No segundo caso, slip, o limite da força de atrito é atingido e, assim, a componente tangencial da força na superfície de cada sólido será igual ao valor deste limite. Não pode haver força tangencial maior que o limite de atrito. A Figura 5.2 ilustra as forças atuantes nas superfícies de cada sólido.

Em ambos os casos, a força tangencial a ser desenvolvida depende da componente normal atuando no mesmo ponto e das características de cada sólido (como a rugosidade, a topologia, etc.).

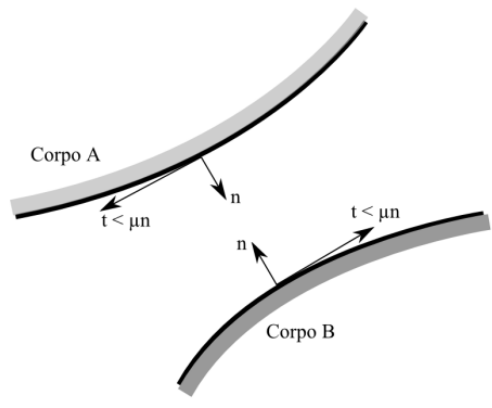

(a)

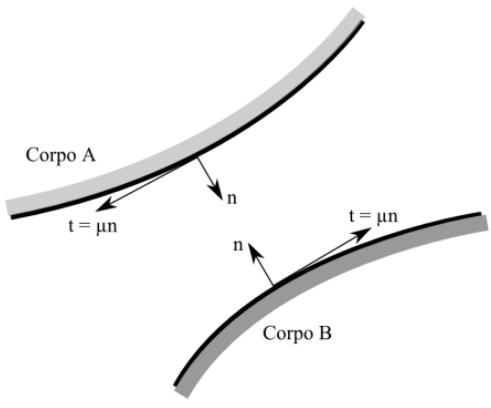

(b)

Figura 5.2 - Contato com atrito. (a) forças em situação tipo stick. (b) forças em situação tipo slip.

O comportamento de fricção pode ser caracterizado por meio da Lei Clássica da Fricção, ou Lei de Fricção de Coulomb. Por esta lei, o deslizamento relativo entre dois sólidos em contato irá acontecer quando a força tangencial em algum ponto da superfície exceder o produto da componente normal e uma constante de atrito (WRIGGERS, 2006). Ou seja 


$$
t_{t}= \pm \mu t_{n}
$$

onde a constante $\mu$ é chamada de coeficiente de atrito e caracteriza o material e a superfície.

A simplicidade desta formulação faz com que a teoria de Coulomb seja amplamente aplicada em modelos de contato (MAN, 1994).

\subsubsection{Contato conforme}

Um contato é dito conforme quando a superfície potencial de contato entre dois sólidos estiver exatamente ajustada num estado sem carregamento. Uma das principais características de um contato conforme é que o tamanho da área de contato independe do carregamento, ou seja, ao final do carregamento a superfície de contato será a mesma daquela na configuração inicial (Fig. 5.3a). Por esta razão, o histórico do carregamento não tem grande importância em problemas desta categoria.

\subsubsection{Contato não-conforme}

Quando o contato acontece em um ponto (semelhante ao contato entre duas esferas) ou ao longo de uma linha (entre um cilindro e uma superfície plana, por exemplo), diz-se que ocorreu um contato não-conforme. Então, pode-se dizer que a área de contato irá mudar com a aplicação do carregamento, sendo neste caso importante o histórico do carregamento. 


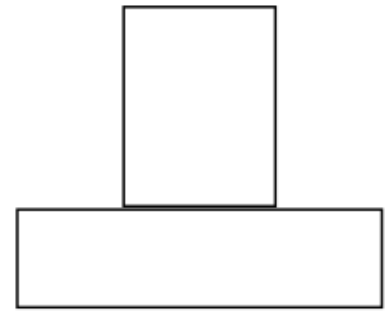

(a)

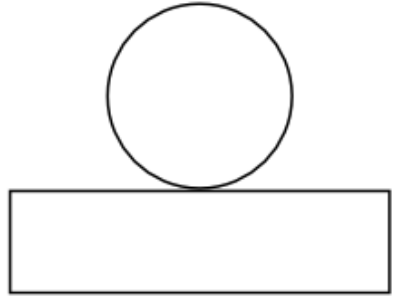

(b)

Figura 5.3 - Tipos de contato: (a) Contato conforme. (b) Contato não-conforme.

\subsection{Algoritmo proposto de contato com o MEC}

De maneira semelhante ao que foi realizado no capítulo 4, agora, para os problemas de contato, o contorno de cada sólido será aproximado por uma malha de elementos de contorno, como ilustrado na Figura 5.4b.

A Figura 5.4a apresenta dois sólidos isotrópicos $A$ e $B$ delimitados pelos contornos $\Gamma^{\mathrm{A}}$ e $\Gamma^{\mathrm{B}}$, respectivamente. Em uma situação de contato, cada contorno pode ser dividido em duas regiões: região de contato $\Gamma_{c}$; e região de não-contato $\Gamma_{n c}$ (Fig. 5.4c). De forma que

$$
\Gamma=\Gamma_{\mathrm{c}}+\Gamma_{\mathrm{nc}}
$$

$\mathrm{Na}$ interface de contato, os nós não possuem deslocamentos ou tensões prescritas, diferentemente dos demais nós do contorno $\Gamma_{\mathrm{nc}}$. Por outro lado, as condições de equilíbrio e compatibilidade devem ser satisfeitas. Desta forma, em cada par de nós em contato existem oito incógnitas, quatro em força e quatro em deslocamento. Estas incógnitas devem ser compatibilizadas e equilibradas segundo as características de contato apresentadas anteriormente, seção 5.1 (BECKER, 1992).

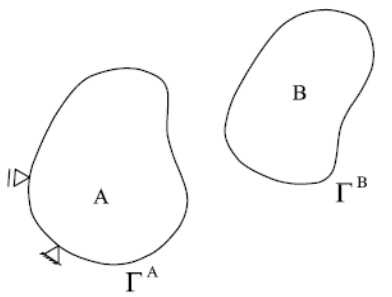

(a)

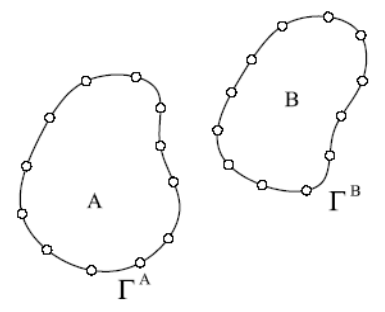

(b)

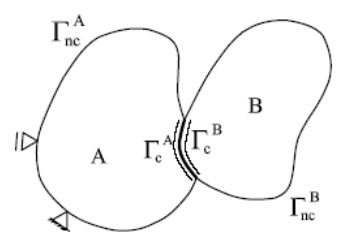

(c)

Figura 5.4 - Representação de dois sólidos em um problema de contato. (a)Sólidos A e B. (b) 
Discretização pelo MEC. (c) Sólidos A e B em contato.

Neste trabalho, serão consideradas três situações possíveis para descrever o contato no decorrer do processo. Chama-se de "modo de contato" o estado que caracteriza um dado par de nós da superfície potencial. Cada modo deve satisfazer as condições de contato apresentadas em 5.1.

\subsubsection{Modo de contato 1 (separação)}

O modo 1 é caracterizado pela ausência de contato, ou seja, quando o par de nós encontra-se separado.

Neste caso, as seguintes condições de contato devem ser aplicadas:

$$
\begin{aligned}
& t_{x}^{(A)}=0, \\
& t_{y}^{(A)}=0, \\
& t_{x}^{(B)}=0 \mathrm{e} \\
& t_{y}^{(B)}=0 .
\end{aligned}
$$

Os índices $x$ e $y$ representam as direções principais do sistema global de coordenadas. 


\subsubsection{Modo de contato 2 (sem deslizamento)}

O modo 2 é aplicado quando existe contato sem que haja deslizamento. Em um par de nós inicialmente separados que são levados ao contato sem violar o critério de Coulomb aplica-se o modo 2. Assim, as seguintes equações devem ser adicionadas:

$$
\begin{gathered}
u_{n}^{(A)}+u_{n}^{(B)}=g a p^{A B}, \\
u_{t}^{(A)}+u_{t}^{(B)}=0, \\
t_{n}^{(A)}-t_{n}^{(B)}=0 \mathrm{e} \\
t_{t}^{(A)}-t_{t}^{(B)}=0 .
\end{gathered}
$$

onde $g a p^{A B}$ é a distância inicial entre os nós; $n$ e $t$ referem-se às direções normal e tangencial na superfície daquele ponto de contato. Nas equações Eq. 5.7 à Eq. 5.10 considera-se o sistema de coordenadas local.

Este modo também é usado quando um par de nós encontra-se inicialmente em contato e não desenvolve deslizamento ao longo do processo. Neste caso, considera-se gap ${ }^{A B}=0$. 


\subsubsection{Modo de contato 3 (com deslizamento)}

O modo 3 ocorre quando há deslizamento. Neste modo, o critério de Coulomb foi violado e a força tangencial deve ser dada de acordo com o limite de atrito para o material. As seguintes equações caracterizam este modo:

$$
\begin{gathered}
u_{n}^{(A)}+u_{n}^{(B)}=g a p^{A B} \\
t_{t}^{(A)} \pm \mu t_{t}^{(B)}=0 \\
t_{n}^{(A)}-t_{n}^{(B)}=0 \\
t_{t}^{(A)}-t_{t}^{(B)}=0
\end{gathered}
$$

De forma semelhante ao modo 2, quando um par de nós encontra-se inicialmente em contato e desenvolve deslizamento ao longo do processo, deve-se considerar $\operatorname{gap}^{A B}=0$.

Nota-se que neste caso a compatibilidade dos deslocamentos é feita apenas na direção normal ao contato.

\subsubsection{Estratégia de modelagem}

Visto que os problemas de contato possuem um caráter não-linear, devido às mudanças desconhecidas na área de contato, deve-se empregar alguma técnica que trate este problema de forma iterativa linear. A técnica que será adotada neste trabalho fundamenta-se 
em aplicar o carregamento de forma incremental, ou seja, dividindo-o em partes iguais e aplicando-o gradativamente. Desta maneira, as deformações em cada passo de carregamento serão pequenas o suficiente para que possam ser tratadas linearmente.

Inicialmente deve-se definir uma superfície potencial de contato. Esta é a superfície estimada para o contato e, portanto, deverá ser grande o suficiente para que, ao final do carregamento, não haja contato em alguma outra parte do sólido que não esta que foi especificada.

Deve-se também identificar na superfície potencial os pares de nós e os pares de elementos. Um par é definido com um nó, ou elemento, de cada sólido. Neles serão feitas as análises de contato ao longo do processo para que os modos de contato possam ser aplicados. A Figura 5.5 ilustra as superfícies potenciais de contato para cada sólido (linhas verde e amarelo), e os pares de nós com o seu respectivo modo de contato em um certo momento do carregamento.

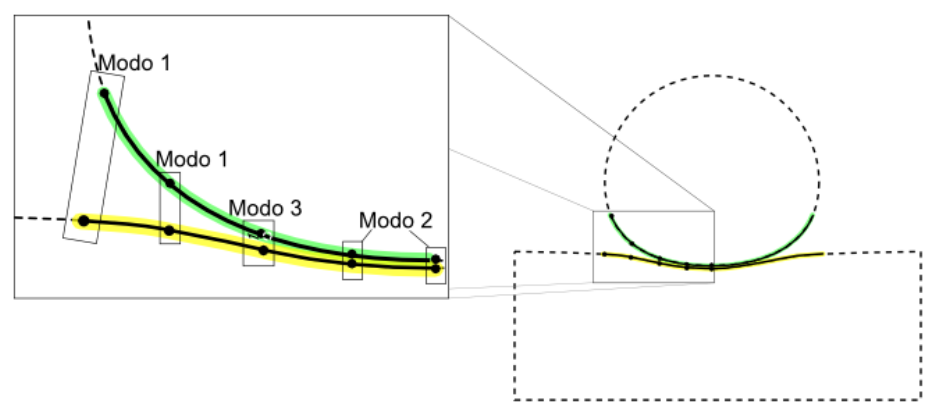

Figura 5.5 - Representação da superfície de contato, dos pares de nós e modos de contato.

As matrizes $\mathbf{H}$ e $\mathbf{G}$ do sistema da Eq. (4.9) devem ser calculadas independentemente para cada sólido do problema. Uma vez que os sistemas de equações do MEC estejam definidos para cada região, a compatibilidade e o equilíbrio na superfície de contato devem ser estabelecidos para que o acoplamento seja feito e o sistema possa ser resolvido de forma simultânea para ambas as regiões.

Em um par de nós existem oito incógnitas: $u_{x}^{A}, u_{y}^{A}, u_{x}^{B}, u_{y}^{B}, t_{x}^{A}, t_{y}^{A}, t_{x}^{B}, t_{y}^{B}$. De acordo com a formulação do MEC descrita anteriormente, cada nó adiciona duas equações no sistema da Eq.(4.9). Assim, para cada par de nós devem ser adicionadas mais quatro equações. Estas quatro equações são definidas para cada modo de contato. 
Os modos de contato devem ser inseridos de forma explícita, ou seja, cada equação dada em 5.2.1, 5.2.2 ou 5.2.3 será colocada como uma nova linha no sistema acoplado (do tipo dado pela Eq.(4.10)). Esta forma de inserção aumenta o custo computacional por tornar ainda maior o sistema a ser resolvido. Porém, ela permite que novos modos de contato sejam implementados de forma simples, podendo tornar o sistema mais adaptável (MAN, 1994). No novo sistema, a matriz $\mathbf{A}$ da Eq. (4.10) contém elementos das matrizes $\mathbf{H}$ e $\mathbf{G}$ de ambos os sólidos, equações de contato e valores nulos. O sistema acoplado é igual a

$$
\left[\begin{array}{c|c|c:c}
\mathrm{H}_{\mathrm{nc}}^{\mathrm{A}}-\mathrm{G}_{\mathrm{nc}}^{\mathrm{A}} & 0 & \mathrm{H}_{\mathrm{c}}^{\mathrm{A}}-\mathrm{G}_{\mathrm{c}}^{\mathrm{A}} & 0 \\
\hline 0 & \mathrm{H}_{\mathrm{nc}}^{\mathrm{B}}-\mathrm{G}_{\mathrm{nc}}^{\mathrm{B}} & 0 & \mathrm{H}_{\mathrm{c}}^{\mathrm{B}}-\mathrm{G}_{\mathrm{c}}^{\mathrm{B}} \\
\hline 0 & 0 & \text { Condições de contato }
\end{array}\right]\{\mathrm{X}\}=\{f\}
$$

O problema é resolvido de forma incremental e a solução final do problema será aquela encontrada quando todo o carregamento tiver sido aplicado. Em cada incremento os modos de contato serão definidos para cada par de nós de acordo com o seu comportamento atual (BECKER, 1992).

Durante a aplicação do carregamento, os pares de nós devem ser analisados a fim de que um dos modos de contato seja definido. A decisão do modo de contato a ser aplicado deve ser feita ao final de cada incremento e seguindo as seguintes considerações:

1. Verificar se existe abertura entre os nós. Havendo algum espaçamento, deve-se aplicar o modo 1 .

2. Verificar se as forças tangenciais à superfície atingiram o limite de atrito. $\mathrm{O}$ modo 2 deve ser aplicado quando este limite não for atingido e, caso contrário, aplica-se o modo 3. Em ambos os casos, o valor do $g a p^{A B}$ será igual à distância inicial entre os nós.

A Figura 5.6 descreve o algoritmo para uma análise deste tipo. 


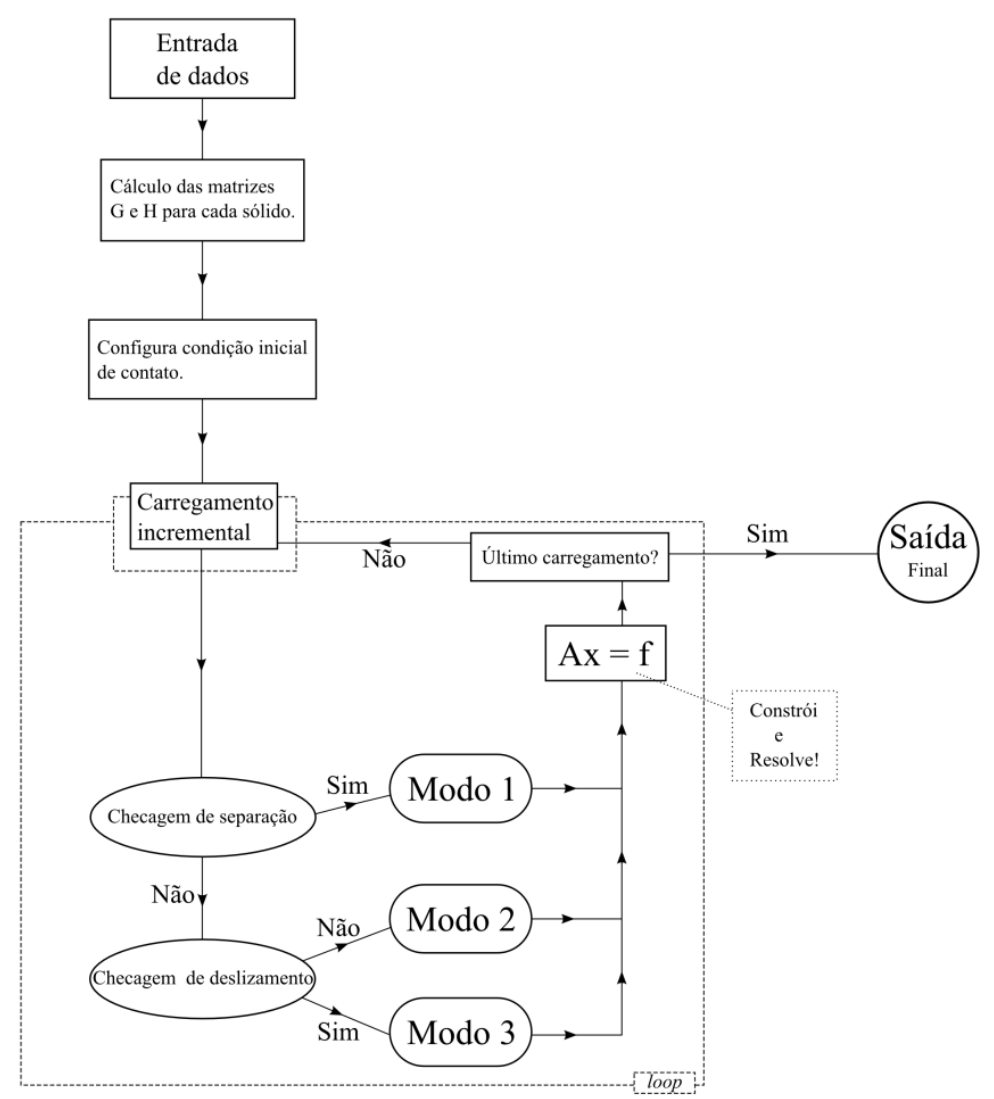

Figura 5.6 - Algoritmo de contato. 


\section{Exemplos Numéricos}

\section{Capítulo}

Neste capítulo apresentam-se os exemplos numéricos com o objetivo de validar o algoritmo de contato para modelagem numérica bidimensional com o MEC, cujo desenvolvimento encontra-se no capítulo 5. A validação é feita comparando os resultados obtidos pelo referido algoritmo com resultados analíticos encontrados na literatura. Além disso, utiliza-se o programa ADINA para realizar análises pelo MEF e compará-las com os modelos propostos.

Vale ressaltar que este algoritmo de contato foi incorporado a uma plataforma computacional que vem sendo desenvolvida sob a coordenação do Prof. Dr. Marcos Noronha para modelagem numérica utilizando o MEC.

Escolheu-se dois exemplos clássicos da mecânica do contato para a validação do algoritmo proposto. Enquanto o primeiro exemplo tem como objetivo analisar um caso de contato não-conforme, o segundo exemplo apresenta a modelagem de contato do tipo conforme. 


\subsection{Cilindro em fundação elástica}

Este é um exemplo clássico disponível na literatura cuja solução analítica foi proposta por Hertz ${ }^{1}$. Trata-se de um cilindro de raio R carregado com uma força de compressão normal $F_{n}$ aplicada em seu topo e apoiado sob uma superfície plana elástica (Fig. 6.1). O objetivo deste exemplo é analisar a distribuição de tensões ao longo da superfície de contato entre os dois sólidos. Para tanto, faz-se a comparação entre a solução analítica proposta por Hertz e a solução dada pelo algoritmo de contato desenvolvido neste trabalho.

É importante ressaltar que neste tipo de problema o contato inicial acontece em um único ponto, contato não-conforme, e, portanto a área de contato final deve ser determinada de forma gradativa utilizando-se o processo de carregamento incremental.

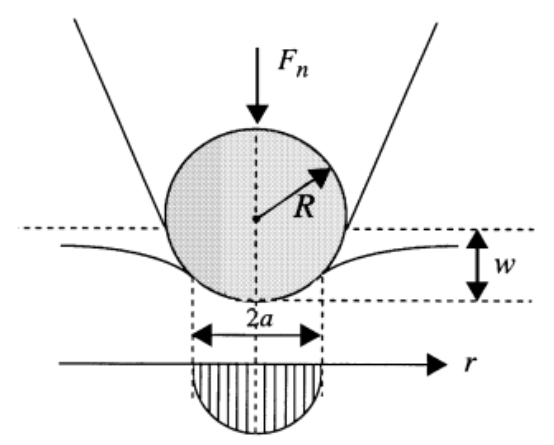

Figura 6.1 - Indentação de um cilindro em uma superfície elástica.

As relações de indentação para deste modelo estão detalhadas em (Barber, 2004; Johnson, 1985; Robert, 2006) sendo dadas por: $a \sim \sqrt[3]{F_{n}}, A_{c} \sim \sqrt[3]{F_{n}^{2}}, w \sim a^{2} / R$, onde $a$ e $A_{c}$ são o raio e a área de contato, respectivamente, do domínio circular de contato, $R$ o raio da esfera, $w$ a penetração a partir da configuração indeformada e $F_{n}$ a força normal aplicada no topo do cilindro. A partir destas proposições pode-se relacionar a penetração do cilindro em termos da força aplicada, ou seja, $F_{n} \sim w^{3 / 2}$. Em termos da distância horizontal $r$ ao eixo de simetria vertical, a pressão pode ser dada segundo a função

\footnotetext{
${ }^{1}$ Heinrich Rudolf Hertz publicou em 1882 o artigo “On the Contact of Elastic Solids”, dando início ao estudo da mecânica do contato (Johnson, 1985).
} 


$$
p(r)=-\frac{4 F_{n} \sqrt{a^{2}-r^{2}}}{\pi a^{2}}
$$

Para este exemplo, a malha de elementos de contorno é composta tanto por elementos quadráticos quanto por elementos lineares. Para a superfície de contato escolheu-se utilizar elementos lineares por se tratar de um problema com área de contato progressiva - cuja área de contato aumenta com a aplicação do carregamento incremental (MAN, 1994). Neste caso, a vantagem dos elementos lineares sobre os quadráticos deve-se ao fato de que um único nó entra em contato por vez, portanto todo o elemento linear estará em contato sempre que um novo nó for adicionado à superfície de contato. Em contrapartida, uma vez que a distribuição de forças de superfície depende da função de forma do elemento, em um elemento quadrático, quando dois de seus nós estão em contato ao mesmo tempo em que o terceiro encontra-se na superfície livre, a representação das forças de superfície não será distribuída de forma coerente visto que as forças na superfície devem ser iguais a zero.

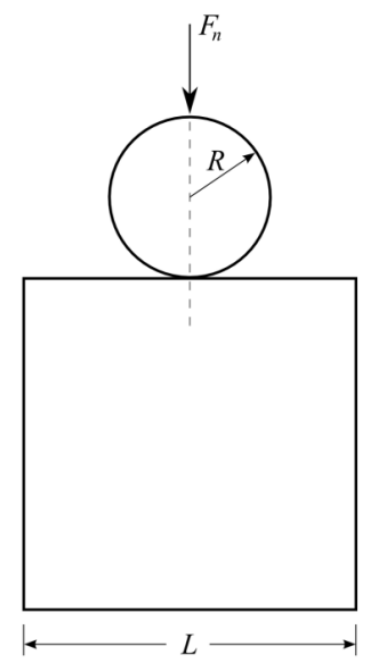

Figura 6.2 - Cilindro em fundação elástica.

A Figura 6.2 representa o modelo estudado. Os parâmetros utilizados neste exemplo são dados na tabela 6.1 a seguir, sendo G o módulo de elasticidade transversal do material 
Tabela 6.1 - Parâmetros dos materiais do cilindro e base.

Parte Parâmetros

\begin{tabular}{|c|c|}
\hline \multirow{4}{*}{ Cilindro } & $\begin{array}{c}-R=0,05 \mathrm{~m} \\
-F_{n}=0,24 \mathrm{~N} \\
-\mathrm{G}=540 \mathrm{~N} / \mathrm{m}^{2}\end{array}$ \\
\hline & $-v=0,35$ \\
\hline & $\begin{array}{l}\text { - } 30 \text { elementos lineares distribuídos uniformemente na superfície } \\
\text { potencial de contato }\end{array}$ \\
\hline & $\begin{array}{l}\text { - } 33 \text { elementos quadráticos distribuídos uniformemente na superfície } \\
\text { livre }\end{array}$ \\
\hline \multirow{5}{*}{ Fundação } & $-\mathrm{L}=0,19 \mathrm{~m}$ \\
\hline & $-\mathrm{G}=540 \mathrm{~N} / \mathrm{m}^{2}$ \\
\hline & $-v=0,35$ \\
\hline & $\begin{array}{l}\text { - } 30 \text { elementos lineares distribuídos uniformemente na superfície } \\
\text { potencial de contato }\end{array}$ \\
\hline & $\begin{array}{l}\text { - } 33 \text { elementos quadráticos distribuídos uniformemente na superfície } \\
\text { livre }\end{array}$ \\
\hline
\end{tabular}

Por se tratar de um problema de contato não-conforme a sua solução depende do histórico do carregamento, portanto este deve ser aplicado de forma incremental.

Para avaliar os resultados obtidos numericamente pelo algoritmo de contato proposto, compararam-se os valores das tensões na superfície de contato tomando como base a solução analítica de Hertz, Eq. 6.1.

Na Figura 6.3 está representada a distribuição da tensão normal ao longo da superfície de contato do cilindro. De acordo com resultado exato, as tensões são máximas exatamente abaixo do eixo de simetria e tendem a zero na borda da superfície de contato. A comparação 
entre os resultados mostra que as tensões calculadas pelo MEC apresentam-se bastante precisas para este modelo.

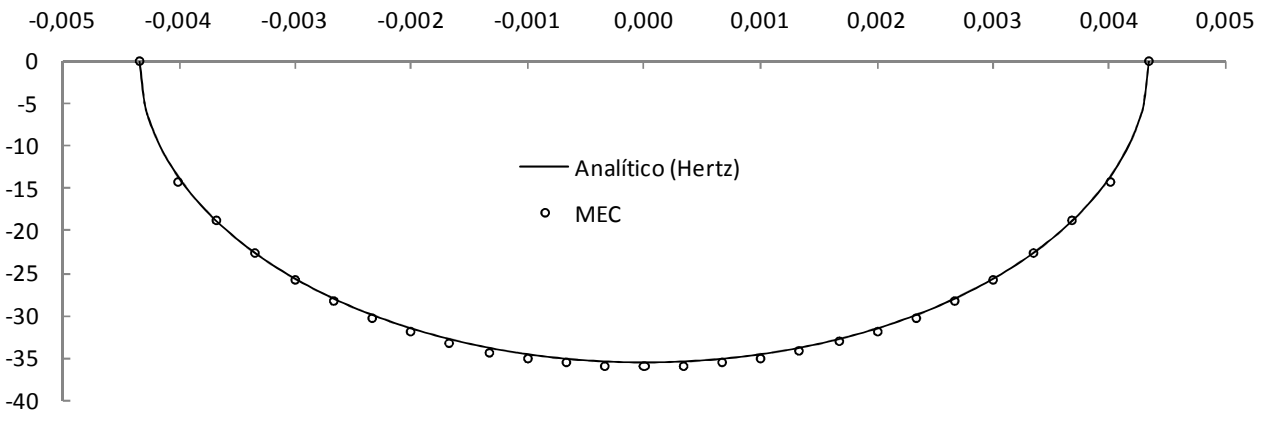

Figura 6.3 - Distribuição da tensão normal na superfície de contato.

\subsection{Exemplo 2 - Pilar em uma fundação elástica}

O segundo teste de validação consiste em analisar a penetração de um pilar em uma fundação elástica (Fig. 6.4). Para isso, os resultados encontrados por meio do algoritmo descrito neste trabalho serão confrontados com um modelo semelhante do MEF utilizando o programa ADINA. A visualização dos resultados pelo MEC será feita utilizando a técnica de visualização desenvolvida por Pereira (2004)².

\footnotetext{
${ }^{2} \mathrm{O}$ algoritmo proposto por Pereira consiste em traçar as isocurvas de tensão dentro do domínio de forma automática, diferentemente dos demais métodos utilizados para este fim que utilizam pontos internos auxiliares. Este algoritmo de visualização está incorporado à plataforma computacional que vem sendo desenvolvida sob orientação do professor Dr. Marcos Noronha.
} 


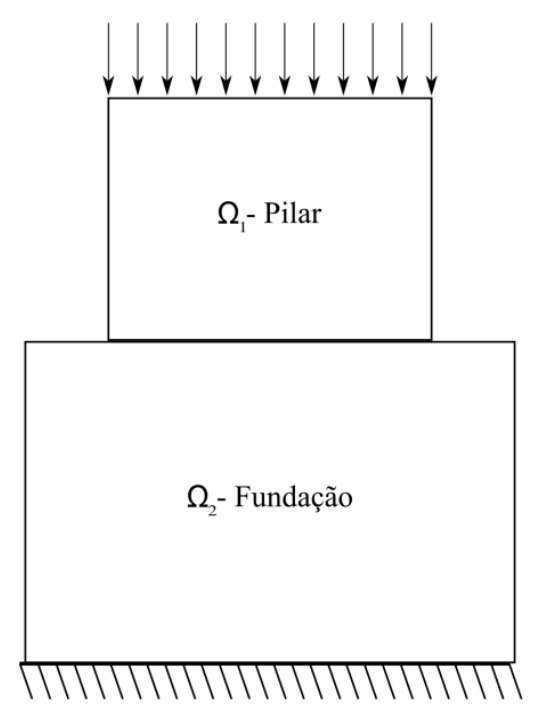

Figura 6.4 - Pilar apoiado em uma fundação elástica.

Para a modelagem pelo MEC utilizou-se 78 nós e 70 elementos. A base elástica é constituída por 44 nós e 36 elementos, sendo 8 elementos quadráticos e 27 elementos lineares. O modelo do pilar constitui-se de 34 nós e 34 elementos, sendo todos estes lineares. Mais uma vez, optou-se por utilizar elementos lineares na superfície de contato.

Para a análise pelo MEF foram criados dois modelos diferentes, diferenciados pelo grau de refinamento da malha discretizada. O primeiro caso representa uma malha pouco refinada na qual são utilizados 65 elementos e 297 nós. O segundo modelo representa uma malha com alto grau de refinamento. Nos pontos onde há concentração de tensão deve-se ter uma malha com discretização mais rigorosa. Entretanto, desconsiderou-se que no restante do modelo não há esta necessidade e todo o modelo recebeu o mesmo grau de refinamento. Desta maneira, foram utilizados 6.000 elementos e 24.341 nós. Em ambos os casos, optou-se pelos elementos quadráticos de 9 nós. A Figura 6.5 ilustra os modelos do MEF e MEC utilizados. 


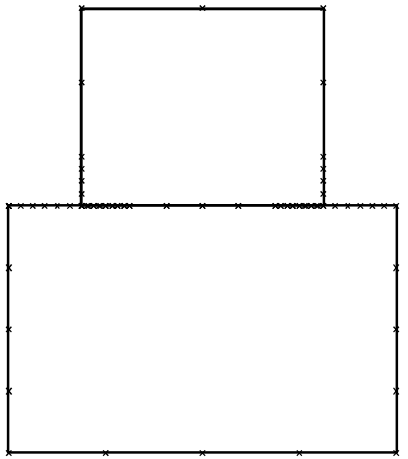

(a)

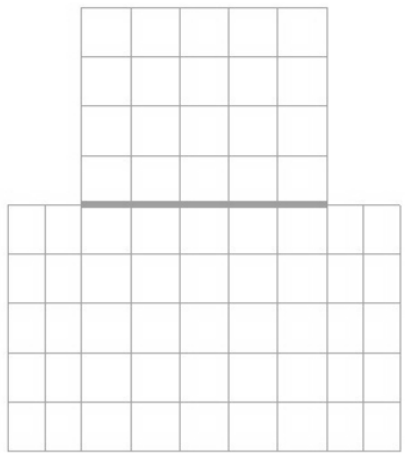

(b)

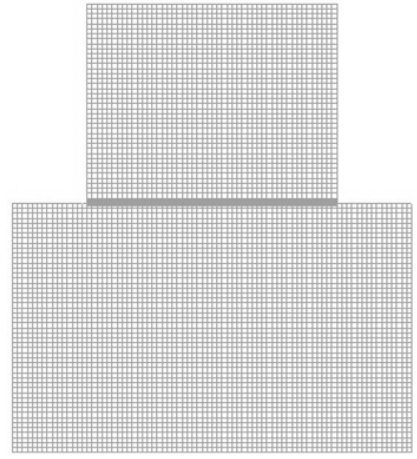

(c)

Figura 6.5 - Discretizações com o MEC e MEF. (a)MEC - 78 elementos e 70 nós. (b) MEF - 65 elementos e 297 nós. (c) $\mathrm{MEF}-6.000$ elementos e 24.341 nós.

Utilizou-se como parâmetro de comparação a penetração da peça na base elástica. Os valores absolutos estão expostos na tabela 6.2. Observa-se que os deslocamentos verticais no centro do pilar convergem tanto numa comparação entre o MEC e o modelo 2 do MEF, cuja malha é mais refinada, quanto com o outro modelo.

Tabela 6.2 - Comparação dos valores de penetração do pilar em uma fundação elástica.

$\begin{array}{lll}\text { Método } & \text { Discretização } & \text { Penetração (m) }\end{array}$

\begin{tabular}{ccc}
\hline MEC & $\begin{array}{c}\text { 70 elementos (61 lineares e 8 quadráticos) - 78 } \\
\text { nós }\end{array}$ & 0.08505 \\
\hline MEF & 65 elemenos -297 nós & 0,08427 \\
\hline MEF & 6.000 elementos -24.341 nós & 0,08496 \\
\hline
\end{tabular}

A Figura Fig. 6.6 representa a configuração deformada em duas situações distintas. Na Figura 6.6(a) apresenta-se a penetração de um pilar com rigidez elevada em uma base flexível. Por outro lado, para o resultado apresentado na Figura 6.6(b), igualou-se a elasticidade de ambas as partes e manteve-se o mesmo carregamento. Nestas duas condições utilizou-se o algoritmo de contato para o MEC. 


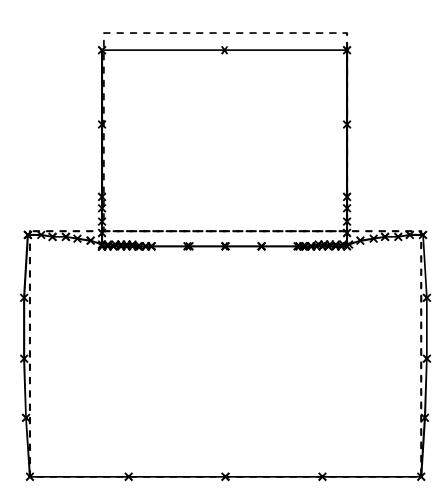

(a)

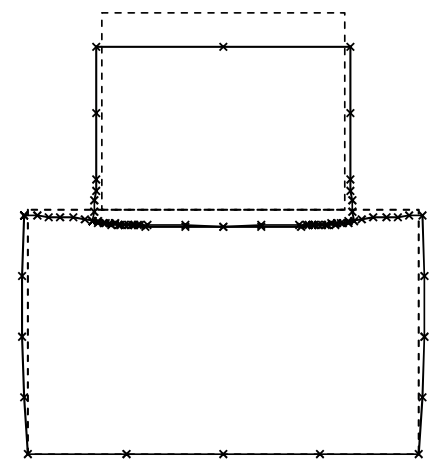

(b)

Figura 6.6 - Configuração deformada de um pilar sobre base flexível. (a) Pilar rígido. (b) Pilar e base flexíveis.

O A figura Fig. 6.7 ilustra as zonas de tensão calculadas para cada modelo, tanto pelo MEC quanto pelo MEF.

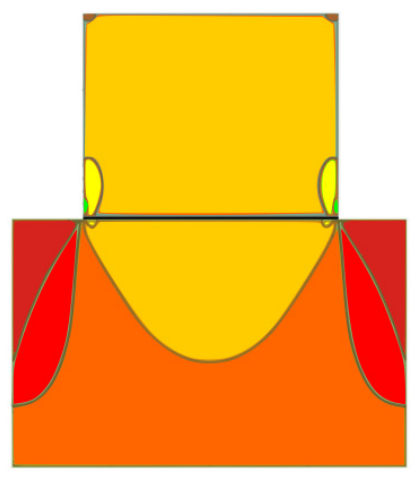

(a)

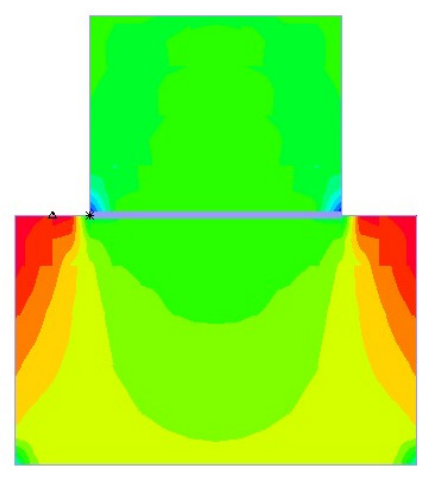

(b)

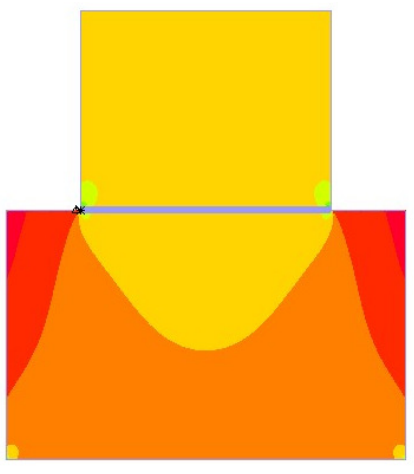

(c)

Figura 6.7 - Zonas de tensão. (a) MEC. (b) MEF - 65 elem. e 297 nós. (c) MEF - 6.000 elem. e 24.431 nós.

Observa-se na Figura 6.7 que há pontos de imprecisão quando se analisam as zonas de tensão calculadas pelo MEF utilizando uma malha pouco refinada, Figura 6.7(b), em comparação com o mesmo modelo com o refinamento mais rigoroso. Comparando-se os modelos gerados pelo MEC e MEF refinado, nota-se que ouve uma boa aproximação entre as isocurvas de tensão para ambos os casos. 


\subsection{Exemplo 3 - Discos de corte em rocha elástica}

Os exemplos apresentados nas seções anteriores caracterizam situações distintas de contato e foram importantes para a validação do algoritmo apresentado. Desta forma, pode-se iniciar o estudo do problema proposto neste trabalho.

Dada a importância da penetração do disco de corte na rocha para o processo de fraturamento e conseqüente funcionamento da escavação com TBMs, analisa-se neste exemplo a penetração do disco e a distribuição de tensões ao longo do maciço. Comparou-se os valores obtidos através do algoritmo proposto com aqueles obtidos por meio do programa ADINA. Em uma segunda análise estuda-se o campo de tensões entre dois discos de corte quando se altera o espaçamento entre os mesmos. Conforme mencionado no capítulo 2, este tipo de verificação é fundamental para o estudo do processo de formação dos fragmentos de rocha durante uma escavação.

O modelo consiste em dois discos de corte paralelos atuando sobre uma base sólida, (Fig. 6.8). Nas análises aqui descritas considera-se que todos os materiais possuem comportamento do tipo elástico linear ${ }^{3}$, conforme descrito no capítulo 3. O perfil do disco baseia-se no modelo de seção constante usual disponível na literatura, como pode ser visto em (Kolymbas, 2005). Foram feitas duas simulações com os discos de corte. Na primeira delas, considerou-se que a superfície do disco possui cantos arredondados. Nesta análise compara-se a penetração dos discos de corte utilizando-se como parâmetro os valores calculados pelo programa ADINA. No segundo caso, supõe-se que as bordas dos discos são arestas com cantos retos. Para este modelo, compara-se a distribuição de tensões no maciço quando alterado o espaçamento entre os discos para um mesmo carregamento.

\footnotetext{
${ }^{3}$ Certamente, o modelo elástico-linear não é o mais adequado para descrever o comportamento das rochas. Entretanto, vale ressaltar que o objetivo deste trabalho é desenvolver uma proposta de análise da interação entre discos de corte e rocha utilizando-se os conceitos da mecânica do contato com o MEC.
} 


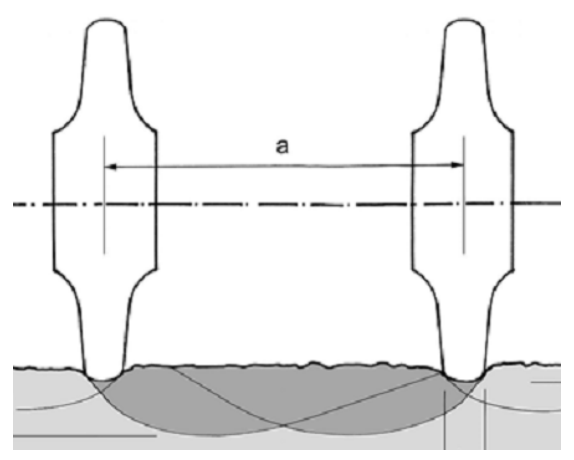

Figura 6.8 - Discos de corte paralelos.

A discretização do contorno pelo MEC contém 132 elementos e 168 nós distribuídos de acordo com a Tabela 6.3 indicado. Para o modelo de comparação do MEF utilizou-se 1.136 e 18.907 elementos e 4.697 e 19.269 nós para os modelos 1 e 2, respectivamente.

Tabela 6.3 - Discretizações pelo MEC e MEF.

\begin{tabular}{ccc}
\hline Parte/Modelo & Nós & Elementos \\
\hline Disco 1 - MEC & 52 & 38 \\
& & $(24$ lineares e 14 quadráticos) \\
\hline Disco 2- MEC & 52 & 38 \\
& & $(24$ lineares e 14 quadráticos) \\
\hline Base - MEC & 64 & 56 \\
& & $(48$ lineares e 16 quadráticos $)$ \\
\hline MEF 1 & 4.697 & 1.136 \\
\hline MEF 2 & 19.269 & 18.907 \\
\hline
\end{tabular}

$\mathrm{Na}$ primeira análise, na qual compara-se a penetração para os modelos do MEC e MEF, verificou-se mais uma vez que há convergência entre os valores calculados pelos dois métodos numéricos. De acordo com a Tabela 6.4 nota-se que a resposta dada para o modelo de contato do MEC está no intervalo entre os resultados dos modelos com maior e menor refinamento utilizados no programa ADINA. 
Tabela 6.4 - Comparação dos valores de penetração do pilar em uma fundação elástica.

\begin{tabular}{ccc}
\hline Método & Modelo & Penetração (m) \\
\hline MEC & Modelo padrão & 0,117359 \\
MEF & MEF 1 & 0,117660 \\
MEF & MEF 2 & 0,115568 \\
\hline
\end{tabular}

No segundo modelo de contato, cujos discos possuem cantos retos, altera-se o espaçamento entre os discos com o intuito de analisar a zona de tensão entre os mesmos. A Figura 6.9 ilustra os campos de tensão para os diferentes espaçamentos. Dentre os casos analisados, a figura superior representa os discos na configuração de maior espaçamento, sendo a última imagem aquela que representa a situação de maior proximidade entre os cortadores. Nota-se que há uma evolução na tensão entre os cortadores à medida que estes se aproximam um do outro.
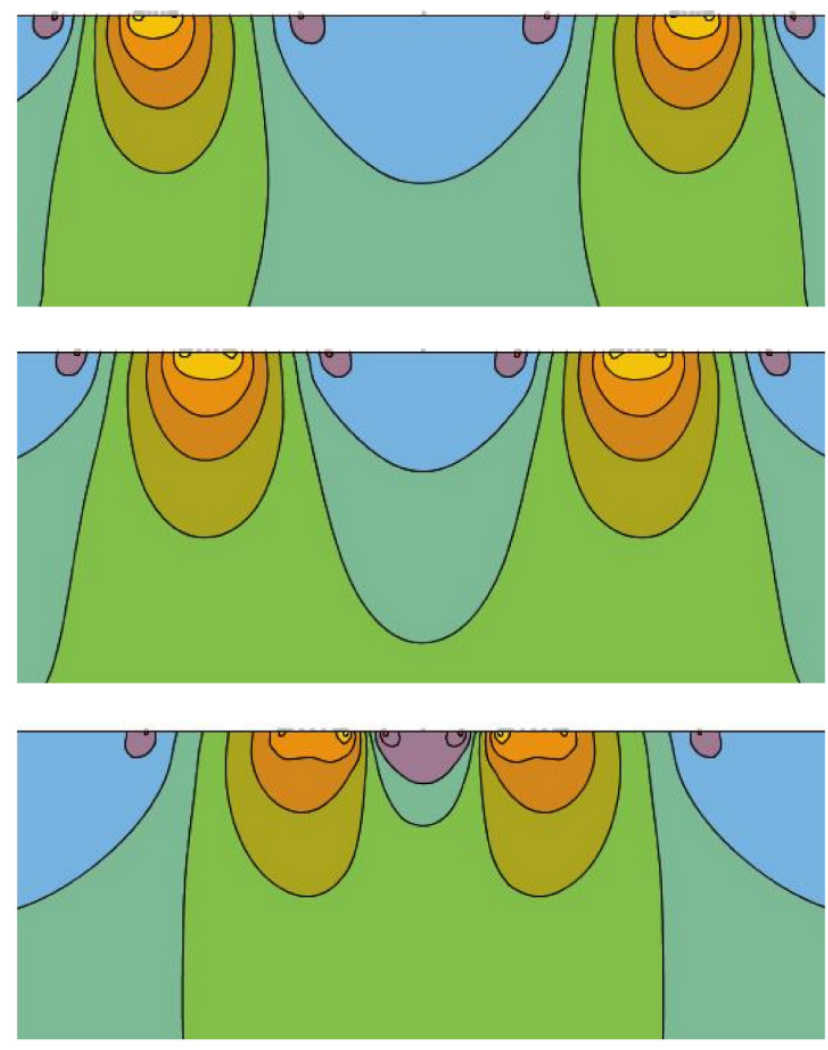

Figura 6.9 - Evolução das tensões entre dois discos de corte com a diminuição do espaçamento. 
A figura 6.10 ilustra a evolução do espaçamento entre os cortadores para a análise demonstrada na figura 6.9.
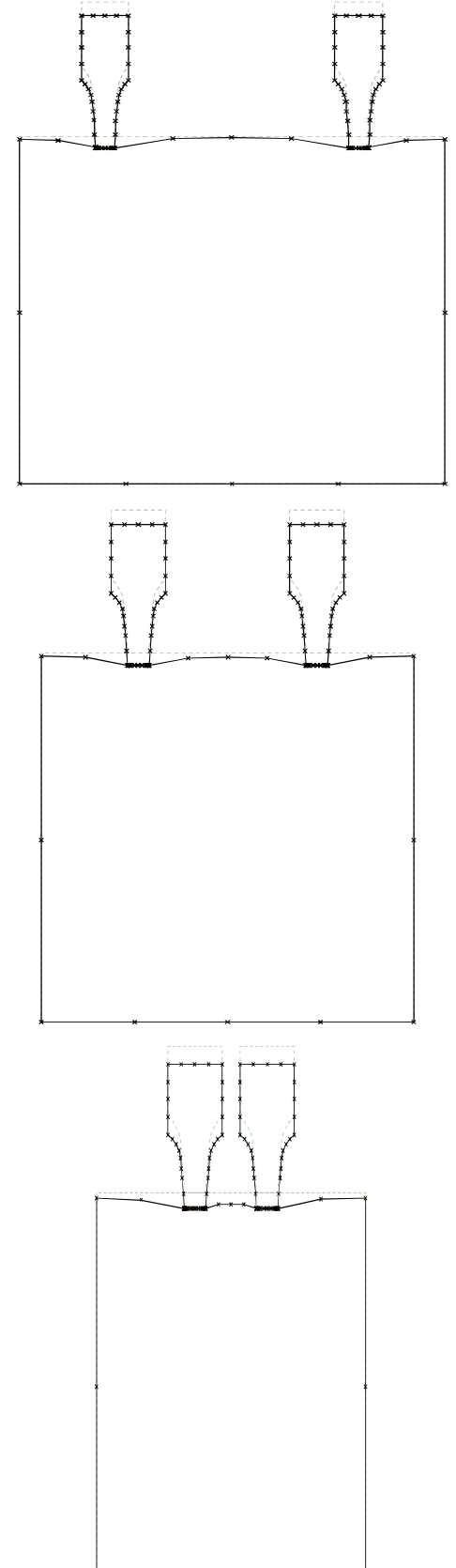

Figura 6.10 - Discos de corte em espaçamentos diferentes. 


\section{Considerações Finais}

\section{Capítulo}

Esta seção traz as considerações finais do trabalho realizado, discutindo as conclusões e apresentando as sugestões para trabalhos futuros. Foram analisados os aspectos relativos ao uso do MEC com a mecânica do contato como uma ferramenta de análise para simulações de escavação com máquinas tuneladoras.

\subsection{Conclusões}

Conclui-se com os testes realizados que o algoritmo de contato proposto, comparado com outras técnicas numéricas baseadas no $\mathrm{MEF}$, apresentou resultados bastante satisfatórios, mostrando que é possível trabalhar com uma discretização simples com poucos elementos de contorno para a representação dos problemas de contato entre TBMs e maciços rochosos. Desta forma, simulações mais complexas incluindo os diferentes efeitos necessários para a simulação da ação dos cortadores podem ser realizadas já que não há problemas em trabalhar com MEC em problemas de contato. A simplicidade da malha é uma vantagem do MEC em relação a outros métodos numéricos utilizados para este fim, sendo esta uma das motivações que levaram à escolha desta ferramenta de análise para o presente trabalho.

O MEC, quando comparado com outros métodos tem sido pouco utilizado para este tipo de análise. Isto pode ser em decorrência de algumas limitações que existiam das quais muitas delas já foram aprimoradas, como o problema com a visualização dos resultados, o qual uma proposta de solução foi apresentada por Pereira (2004) e Pereira e Noronha (2009), e o problema com integrais singulares que foi tratado por Noronha (1998).

Nos últimos anos, houve um crescimento significante no uso de TBMs, porém, em diversas bibliografias consultadas, constatou-se que há deficiência em estudos numéricos para este tipo de equipamento. Em todos os trabalhos consultados, este tipo de análise é feita com base em dados empíricos ou considerando que a transmissão de efeitos da máquina contra o 
maciço é dada por um conjunto de forças, o que pode tornar a análise menos eficiente. Portanto, acredita-se que a técnica apresentada neste trabalho representará uma ferramenta auxiliar com precisão para modelagem de escavações.

É importante mencionar que apesar de o algoritmo funcionar perfeitamente para os propósitos deste trabalho, notou-se que há certa dificuldade para modelagem de problemas onde há grande desconformidade da malha. Este problema afeta, por exemplo, os casos em que há grandes deformações e os nós de um par tendem a se afastar muito um do outro, ou quando é necessário definir uma superfície potencial de contato com grandes afastamentos iniciais.

Em um estudo à parte envolvendo contato não-conforme, o qual um pino com ponta circular era forçado a penetrar em um solo com base plana e elástica, notou-se que, à medida que o pino penetra e consequentemente novos nós são levados ao contato, um dado nó do pino que esteja localizado no mesmo eixo vertical e acima do nó da base, tal que estes estejam referenciados como um par, não terá o ponto de encontro no eixo normal que liga estes dois pontos na configuração indeformada. Isto causa uma desconformidade no momento do contato e, como conseqüência, a posição final destes nós poderá ser em um ponto levemente fora da superfície.

Em análises de contato com o MEC deve-se atentar para o fato de que as superfícies dos sólidos são aproximadas por funções de interpolação que consideram como parâmetro valores pontuais, os nós. Desta maneira, quando a borda da superfície de contato estiver localizada entre dois nós, um nó em contato e outro na superfície livre, a função de interpolação naquele elemento poderá não ser adequada para representar a força de superfície que se desenvolve em tal região. Isto implica que deve-se escolher uma discretização razoável em zonas que podem estar sujeitas a situações deste tipo.

Neste trabalho, optou-se por utilizar a técnica de carregamento incremental que considera o passo de carregamento igual em todo o processo. Este tipo de consideração pode levar ao problema que foi citado no parágrafo anterior. Durante as análises, observou-se que pode haver concentração de tensão nos nós próximos à borda do contato quando tal situação é verificada. Para explicar este fato deve-se recordar alguns detalhes considerados na implementação, são estes: um elemento é dito em contato quando dois ou mais de seus nós estão em contato; um elemento que não está em contato possui força de superfície conhecida e igual a zero (ou algum valor referente à pressão externa); um nó é dito em contato quando a 
diferença de deslocamento entre este nó e o seu par for igual à abertura inicial entre eles. Desta maneira, quando a borda do contato estiver entre dois nós, o que seria resistido pela parcela que está em contato do elemento em "semi-contato" será distribuído para o restante da superfície e a maior parcela será resistida pelo nó mais próximo à borda. Assim, é desenvolvida a concentração de tensão. A situação ideal acontece quando o a borda do contato está exatamente em um nó. Uma forma de reduzir este efeito é utilizar alguma técnica de estimativa do incremento de força. Uma técnica destinada a este fim foi aplicada em outros trabalhos, como por exemplo MAN (1994), e baseia-se em calcular o incremento com base em uma extrapolação linear que irá definir qual a força necessária para levar o próximo par de nós ao contato. Isto requer uma análise que relacione o histórico do carregamento e a respectiva deformação.

É importante ressaltar que o algoritmo proposto pode ser facilmente estendido para outras aplicações, como por exemplo, para análise não-linear com o MEC. Além disso, o uso da POO permite que novos modos de contato possam ser adicionados ao modelo sem maiores problemas, como por exemplo, um modo de auto-contato.

\subsection{Sugestões para trabalhos futuros}

- Adequação do algoritmo de pré-processamento da plataforma para problemas de contato;

- Extensão deste algoritmo de contato para problemas de auto-contato, aprimorando-o para situações envolvendo grandes deformações, e tornar o algoritmo mais genérico. Além disso, novos estudos devem ser feitos a fim de aplicar a técnica de malha não-conforme no algoritmo proposto;

- Implementar e realizar testes com elementos descontínuos, pois espera-se que com este tipo de elemento pode-se reduzir ou até eliminar o problema de concentração de tensão que foi descrito;

- Analisar o comportamento do modelo de interação rocha-discos de corte, considerando como efeito inicial a penetração do disco ao invés da força que é aplicada nos cortadores;

- Estudo da técnica de contato com MEC para problemas que envolvem efeitos dinâmicos, como o efeito do movimento dos discos de corte; 
- Implementação da metodologia para análise de problemas de visco- e elasto-plasticidade considerando, dentre os mais usuais, os critérios de resistência específicos para rochas, como o critério de Hoek-Brown. 


\section{REFERÊNCIAS BIBLIOGRÁFICAS}

BANERJEE, P. K.; PAPE, D. A., "Treatment of body forces in $2 d$ elastostatic bem using particular integrals". Winter Annual Meeting, Boston, MA, 1987;

BARTON, N., "TBM Tunnelling in Jointed and Faulted Rock", A. A. Balkema/Rotterdam/Brookfield, 2000;

BECKER, A. A., "The Boundary Element Method in Engineering - A complete course". McGraw-Hill International (UK) Limited, 1992;

BEER G., DUENSER C., NORONHA M., "A New Concept for the Numerical Simulation of Tunnel Excavation”, Int. Conf. on Computational \& Experimental Engn. and Sciences, Corfu, Grécia, 2003a.;

BEER G., DUENSER C., NORONHA M., "Numerical Simulation of Geotechnical Problems using the Boundary Element Method - Recent Advances", 4th International Workshop on Applications of Computational Mechanics in Geotechnical Engineering, Ouro Preto / Brasil, 2003b;

BEER G., DUENSER C., NORONHA M., "Recent advances in the numerical simulation of tunnel excavation”, ISRM, Johannesburg, África do Sul, 2003c;

BLAZQUEZ A., PARIS F., CANAS J., "Interpretation of the problems found in applying contact conditions in node-to-point schemes with boundary element non-conforming discretizations”. Engineering Analysis with Boundary Elements, 1998.

BOWERMAN, L.D., MONSEES, J.E., “Rapid Excavation and Tunneling Conference'93”, Proceedings of the RETC Conference, Boston/USA, Cushing-Malloy, 1993;

BREBBIA, C. A.; DOMINGUES, J., "Boundary element method: an introductory course". Southampton: Comp. Mech. Publications, 1989;

BREBBIA, C. A.; TELLES, J. C. F.; WROBEL, L. C., "Boundary element techniques". Berlin: Springer-Verlag, 1984;

CARBONE, M., "Desenvolvimento de um Novo Algoritmo para Análise Viscoplástiva com o Método dos Elementos de Contorno”. Dissertação (Mestrado) - Escola Politécnica, Universidade de São Paulo. São Paulo, 2007;

CEleStiNO, T. B., KOSHIMA, A., TelleS, R. C. D. A., ASSIS, A., "Túneis do Brasil”, Comitê Brasileiro de Túneis, Dória Books and Art, São Paulo, 2006; 
CHIAIA, B., "Fracture mechanics induced in a brittle material by a hard cutting indenter" International Journal of Solids and Structures, v. 38, p. 7747-7768, 2000;

CIGLA M., YAGIZ, S., OZDEMIR, L., "Appliction of Tunnel Boring Machines in Underground Mine Development”, Excavation Engineering \& Earth Mechanics Institute, Department of Mining Engineering, Colorado School of Mines, Golden, Colorado, USA, 2001;

DANDEKAR, B. W; CONANT, R. J., "Numerical analysis of elastic contact problems using the boundary integral equation method. Part 1: Theory”, International Journal for Numerical Methods in Engineering, v. 33, p. 1513-1522, 1992;

FISCHER-CRIPS, A. C., "Introduction to Contact Mechanics", Springer Science and Business Media, 2007";

GAUL, I.; KOGL M. ; WAGNER M., "Boundary element methods for engineers and scientistis: an introductory course with advanced topics”. Springer, 2003;

HUESMAN, A; KUNHN G. "Automatic load incrementation technique for plane Elastoplastic frictional contact problems using boundary element method", Computers \& Structures, v. 56, p. 733-744, 1995;

HUNTER, P., “FEM, MEM Notes”. Department of Engineering Science, 2001;

JOHNSON , K. L., “Contact Mechanics”, Cambridge University press, 1985;

JONES, I.A. et al. "Efficient object-oriented implementation of boundary element software." ToppingBHV, editor. Eighth Int Conf Civil Struct Eng Comput. Stirling: Civil-Comp Press, p. 35-7, 2001;

KOLYMBAS, D., "Tunelling and Tunnel Mechanics - A rational approach to tunnelling”, Springer - Velag Berlin Heindelberg, 2005;

LAGE, C., "The application of object-oriented method to boundary elements." Comput. Methods Appl. Mech. and Engrg., v.157, p.205-213, 1998;

LEE K.H.; TAN K.W., “Object-oriented modelling, analysis and concurrency in the boundary element method". Brebbia CA, Rencis J, editors. Boundaryelements XV. Southampton: CMP, p. 595-609, 1993;

LEE K.H.; TAN K.W., "An object-oriented modelling environment for the boundary element method". TanakaM, et al., editors. Boundary elements 12. Southampton: CMP, p. 449-61, 1990; 
LIU, H. Y.; KOU, S. Q.; LINDQVIST, P. A.; TANG, C. A. "Numerical simulation of the rock fragmentation process induced by indenters". International Journal of Rock Mechanics \& Mining Sciences, v. 39, p. 491-505, 2002;

MAN, K. W., "Contact Mechanics using Boundary Elements”, Computational Mechanics Publications, 1994;

MARTIN, D.; ALIABADI M., “A BE hyper-singular formulation for contact problems using non-conforming discretization”, Computers \& Structures, v. 69: p. 557-565, 1998;

MACKERLE, J., "Object-oriented techniques in FEM and BEM: A bibliography (1996)1999)”. Finite Elements in Analysis and Design, v.36, p.189-196, 2000;

MACKERLE, J., "Object-oriented programming in FEM and BEM: a bibliography (19902003)”. Advances of Engineering Software, v.35,p. 325-336, 2004;

MULLER, A. S., “Um Novo Algoritmo para Análises Não-Lineares Utilizando o Método dos Elementos de Contorno”. Dissertação (Mestrado) - Escola Politécnica, Universidade de São Paulo. São Paulo, 2004;

NORONHA, M. A. M. et al. "On a robust implementation of conventional and hybrid boundary element methods using object-oriented programming." Fourth World Cong Comput Mech, Buenos Aires, p. 114, 1998;

NORONHA, M. A. M.; MULLER, A.; PEREIRA, A. M. B. "An object-oriented computacional platform based on design patterns for the BEM implementation”, McMat Mechanics and Materials Conference, Lousiana/USA, 2005;

NORONHA, M.A.M; PEREIRA, A. M. B., "A New Algorithm for Visualization of Domain Results in Analysis with the Boundary Element Method". $15^{\text {th }}$ International Conference on Boundary Element Tecnology - BETECH, Detroit, USA, 2003;

OLIVEIRA, T. R. S. T.; SAMPAIO, M. A. B.; NORONHA, M. A. M. "Software para Análise Numérica de Túneis com Visualização Usando Método dos Elementos de Contorno". $2^{\circ}$ Congresso brasileiro de túneis e estruturas subterrâneas - Seminário internacional "South American Tunneling”, 2008;

OLUKOKO, O. A; BECKER A. A. "A new boundary element approach for contact problems with friction”, International Journal for Numerical Methods in Engineering, v. 36, p. 2625-2642, 1993;

PEREIRA, A. M. B., “Avanços na visualização, análise não-linear e programação com o método dos elementos de contorno”. Dissertação (Mestrado) - Escola Politécnica, Universidade de São Paulo. São Paulo, 2004; 
PEREIRA, A. M. B.; NORONHA, M. A. M., "Um novo algoritmo gráfico para visualização e subdivisão do domínio em análises realizadas pelo método dos elementos de contorno”. São Paulo, 2002;

PEREIRA, A. M. B.; NORONHA, M. A. M., "Post-processing and visualization techniques in 2D boundary element analysis”. Engineering with Computers Journal, Springer-Verlag London, 2009.

SAMPAIO, M. A. B; NORONHA, M. A. M., "A Contact Mechanics Approach for the Simulation of Rock TBMs Tunneling with the Boundary Element Method". $2^{\text {nd }}$ International Conference on Computational Methods in Tunnelling, 2009;

SAMPAIO, M. A. B.; OLIVEIRA, T. R. S. T.; NORONHA, M. A. M., "Modelagem de máquinas tuneladoras usando a mecânica do contato com o Método dos Elementos de Contorno". $2^{\circ}$ Congresso brasileiro de túneis e estruturas subterrâneas - Seminário internacional "South American Tunneling", 2008;

SOUZA, C. P. G. de, "Análise de alta precisão em modelos tridimensionais de elementos de contorno utilizando técnicas avançadas de integração numérica”. Dissertação (Mestrado) Escola Politécnica, Universidade de São Paulo. São Paulo, 2007;

VENTURINE W.S., "Boundary Element Method in Geomechanics", Springer-Verlag Berlin, Heidelberg, 1983;

WRIGGERS, P., “Computational Contact Mechanics”. Springer-Velag Berlin Heidelberg, 2006;

ZHAO, J., "The Challenge of TBM Excavation in Rock", Tunnels and Tunnelling International, p. 27-29, 2006. 